\title{
Transforming Growth Factor Beta3 is Required for Cardiovascular Development
}

\author{
Mrinmay Chakrabarti ${ }^{1}$, Nadia Al-Sammarraie ${ }^{1}$, Mengistu G. Gebere ${ }^{1} \mathbb{C}$, Aniket Bhattacharya ${ }^{1}$, \\ Sunita Chopra ${ }^{1}$, John Johnson ${ }^{1}$, Edsel A. Peña ${ }^{2}$, John F. Eberth ${ }^{1}{ }^{1}$, Robert E. Poelmann ${ }^{3}$, \\ Adriana C. Gittenberger-de Groot ${ }^{3}$ and Mohamad Azhar $1,4, *$ (i) \\ 1 Department of Cell Biology and Anatomy, University of South Carolina School of Medicine, \\ Columbia, SC 29209, USA; Mrinmay.Chakrabarti@uscmed.sc.edu (M.C.); \\ Nadia.Al-Sammarraie@uscmed.sc.edu (N.A.-S.); Mengistu.Gebere@uscmed.sc.edu (M.G.G.); \\ Aniket.Bhattacharya@uscmed.sc.edu (A.B.); sunita.chopra42@gmail.com (S.C.); \\ John.Johnson@uscmed.sc.edu (J.J.); John.Eberth@uscmed.sc.edu (J.F.E.) \\ 2 Department of Statistics, University of South Carolina, Columbia, SC 290208, USA; pena@stat.sc.edu \\ 3 Department of Cardiology, Leiden University Medical Center, 2333 ZC Leiden, The Netherlands; \\ R.E.Poelmann@lumc.nl (R.E.P.); A.C.Gittenberger-de_Groot@lumc.nl (A.C.G.-d.G.) \\ 4 William Jennings Bryan Dorn VA Medical Center, Columbia, SC 29209, USA \\ * Correspondence: Mohamad.Azhar@uscmed.sc.edu
}

Received: 23 April 2020; Accepted: 20 May 2020; Published: 24 May 2020

check for updates

\begin{abstract}
Transforming growth factor beta3 (TGFB3) gene mutations in patients of arrhythmogenic right ventricular dysplasia/cardiomyopathy (ARVD1) and Loeys-Dietz syndrome-5 (LDS5)/Rienhoff syndrome are associated with cardiomyopathy, cardiac arrhythmia, cardiac fibrosis, cleft palate, aortic aneurysms, and valvular heart disease. Although the developing heart of embryos express $T g f b 3$, its overarching role remains unclear in cardiovascular development and disease. We used histological, immunohistochemical, and molecular analyses of $T g f b 3^{-/-}$fetuses and compared them to wildtype littermate controls. The cardiovascular phenotypes were diverse with approximately two thirds of the Tgfb3 $3^{-/-}$fetuses having one or more cardiovascular malformations, including abnormal ventricular myocardium (particularly of the right ventricle), outflow tract septal and alignment defects, abnormal aortic and pulmonary trunk walls, and thickening of semilunar and/or atrioventricular valves. Ventricular septal defects (VSD) including the perimembranous VSDs were observed in $T g f b 3^{-/-}$fetuses with myocardial defects often accompanied by the muscular type VSD. In vitro studies using TGF $\beta 3$-deficient fibroblasts in 3-D collagen lattice formation assays indicated that TGF $\beta 3$ was required for collagen matrix reorganization. Biochemical studies indicated the 'paradoxically' increased activation of canonical (SMAD-dependent) and noncanonical (MAP kinase-dependent) pathways. TGF $\beta 3$ is required for cardiovascular development to maintain a balance of canonical and noncanonical TGF $\beta$ signaling pathways.
\end{abstract}

Keywords: transforming growth factor beta-3; cardiac development; loeys dietz syndrome-5; arrhythmogenic right ventricular dysplasia; rienhoff syndrome; cleft palate; congenital heart disease; outflow tract septation; signaling networks

\section{Introduction}

Transforming growth factor beta3 (TGFß3) is a multifunctional growth factor and cytokine well-known for its involvement in craniofacial development [1-5]. In humans, the TGFB3 gene is involved in arrhythmogenic right ventricular dysplasia (ARVD) familial 1 (ARVD1) (OMIM\#107970) [6, 7], now being referred to as arrhythmogenic right ventricular cardiomyopathy (ARVC). ARVC involves 
progressive fibrofatty replacement of the myocardium, resulting in ventricular tachycardia and sudden death in young athletes and patients. The ARVC primarily affects the right ventricle (RV) but emerging evidence suggests that it may also affect the left too (LV) [6,8]. Overall, presentation of the disease is highly variable among affected individuals. Furthermore, TGFB3 mutations in Loeys-Dietz Syndrome 5 (LDS5)/Rienhoff syndrome (RNHF) (OMIM\#615582) are associated with connective tissue disorders and Marfan syndrome (MFS)-like features, including congenital heart defects (CHD), aortic aneurysms, and valvular disease [9-11]. For instance, aorta from LDS5 patients exhibit paradoxically increased TGF $\beta$ signaling, which is thought to be involved in the diverse aortopathies [9]. Other features of these patients overlap clinically with Shprintzen-Goldberg syndrome (SGS) (OMIM\#182212) and Marfan syndrome (MFS) (OMIM\#154700), including cleft palate. De novo TGFB3 mutations also cause congenital syndromes characterized by a combination of clinical features of Beals-Hecht syndrome (CCA) (OMIM\#121050), RNHF, MFS, and Loeys-Dietz syndrome (LDS) [12-14].

TGF $\beta 3$ has been implicated in several cellular processes in a context-dependent and tissue-specific fashion, including epithelial-mesenchymal transition (EMT), cell growth, apoptosis, differentiation, extracellular matrix (ECM) production and remodelling, all of which are critical processes involved in both the development and homeostasis of cardiovascular tissues [15-19]. TGF $\beta 3$ interacts with the heteromeric TGF $\beta R 2$ and TGF $\beta R 1$ receptor complex, which results in the phosphorylation and activation of SMAD2 and SMAD3 [20]. In association with SMAD4, the phosphorylated SMAD2/3 molecules migrate to the nucleus [21]. TGF $\beta$ ligands can induce SMAD1/5/9, so-called BMP-driven SMADs, via involvement of BMP Type I receptors in endothelial cells and/or fibroblasts, thereby bringing about crosstalk between TGF $\beta$ and BMP signaling pathways [22]. In addition, TGF $\beta$ ligands can signal through non-SMAD mechanisms, including MAP kinase pathways [23]. Thus, given the non-overlapping, dozens of phenotypes among the TGF 33 ligand knockout mice [24], as well as the multiple TGF $\beta$ signaling pathways that have been identified [25], there are several potential mechanisms through which TGF $\beta 3$ can affect the complex differentiation and morphogenetic processes required to develop the essential components of the heart.

The expression of TGFB3 has been detected in the developing mouse heart and adult human heart $[26,27]$. TGF $\beta$ signaling is a critical contributor to collagen accumulation and defective collagen reorganization during fibrofatty lesion formation in ARVD1 and myocardial fibrosis in the infarcted failing hearts [28]. To address the role of TGF 33 in vivo, two different laboratories independently generated $T g f b 3$ knockout $\left(T g f b 3^{-/-}\right)$mice [1,2]. Unfortunately, $T g f b 3^{-/-}$newborn mice have a cleft palate and die within $24 \mathrm{~h}$ of birth. Although cardiovascular disease was not the focus of the two studies, none of the studies reported any congenital heart defects in the Tgfb3-/fetuses. Consequently, the exact role of TGF $\beta 3$ in cardiovascular development remains unknown. Given the recent reports of genetic involvement of TGFB3 mutations in the cardiovascular disease in humans $[6,7,9,12]$, our paradigm-shifting findings demonstrate that the majority of $T g f b 3^{-/}$fetuses develop both cardiac outflow tract (OFT) and atrioventricular (AV) canal defects and that the loss of $T g f b 3$ leads to major myocardial defects, particularly affecting the right ventricular myocardium. Our data also identify downstream mechanisms and specific components of the SMAD- and MAP kinase (MAPK)-dependent signaling pathways that are involved in cardiovascular malformations in TGFß3-deficient mice.

\section{Materials and Methods}

\subsection{Ethics Statement}

All animal procedures were performed according to the Guidelines for the Care and Use of Laboratory Animals published by the National Institutes of Health and were approved by the Institutional Animal Care and Use Committee of the University of South Carolina (Animal use proposal reference \#: 2451-101423-042519, protocol approval date: 25 April 2019, protocol expiration date: 
25 April 2022) Mice were euthanized by an overdose of isoflurane in a sealed container as approved by the IACUC.

\subsection{Mouse Strains}

Mice were housed at the University of South Carolina Animal Research Facility at the School of Medicine. The Institutional Animal Care and Use Committee (University of South Carolina) approved all mouse breeding and experimental procedures. Tgfb3 ${ }^{+/-}$mice [1] were backcrossed on to a C57BL/6 background for more than 12 generations, and maintained on the C57BL/6 genetic background. $\mathrm{Tg} f \mathrm{b3}^{-/-}$embryos were generated and genotyped as described [1]. Timed mating was performed, and the noontime of the positive vaginal plugs was considered as embryonic day (E) 0.5. The DNA sequence of the Tgfb3 specific primers that were used for genotyping includes: TGGGAGTCATGGCTGTAACT (IMF-10, forward primer), CACTCACACTGGCAAGTAGT (IMR-10, reverse primer). PCR genotyping was done as described [1]. PCR genotyping of embryonic tissues genomic DNA identified wildtype, $T g f b 3^{+-}$, and $T g f b 3^{-/-}$fetuses for experiments.

\subsection{Histology and Immunohistochemistry}

Wildtype, $T g f b 3^{+/-}$, and Tgfb3-/- embryos/fetuses were collected between E13.5 and E18.5 and processed for histological and immunohistochemical, morphometric, and molecular analyses. Hematoxylin and eosin (H\&E) staining was performed on $7 \mu \mathrm{m}$ thick serial sections of the heart for routine histological examination. Immunohistochemistry (IHC) was done on $4 \%$ paraformaldehyde fixed $7 \mu \mathrm{m}$ thick paraffin sections by using immunostaining kits (LSAB2 kit, Universal, HRP Rabbit/Mouse (Cat \#: K0675), according to the protocol of the manufacturer (Agilent Dako, USA), and as previously published [29]. Antigen retrieval was performed in Target Retrieval Solution pH 6.0 (catalog no. S1700; Agilent Dako, USA) for $15-20 \mathrm{~min}$ at $95^{\circ} \mathrm{C}$. Anti-muscle actin (Clone: HHF35, catalog no. M0635; Agilent Dako; 1:50 dilution) immunostained sections were counterstained with hematoxylin nuclear stain. All sections were visualized and photographed under brightfield optics on a Nikon Optiphot-2 (equipped with AxioCam MRc Camera) and EVOS TM FL Auto Imaging System (ThermoFisher, Inc., Grand Island, NY, USA). For photographing elastin autofluorescence in hematoxylin and eosin stained sections, 470/22 excitation and 510/42 emission filters were used on a Zeiss Axiovert 200 (Thornwood, NY, USA) (equipped with Axiocam 503 color camera and ZEN 2.3 SP1 Imaging software).

\subsection{TUNEL Staining}

The TUNEL assay was used to detect apoptosis in outflow tract cushions. Paraffin sections from E13.5-14.5 OFT cushions from wildtype and Tg $f b 3^{-/-}$embryos were subjected to the TUNEL assay using FragEL ${ }^{\text {TM }}$ DNA Fragmentation Detection Kit, Colorimetric - TdT Enzyme (Sigma-Aldrich, Cat\#QIA33, St. Louis, MO, USA). All nuclei were also stained with methyl green (Vector Laboratories). Stained samples were observed with a Nikon E400 light microscope and photographs $(10 \times \mathrm{Obj})$ were used for quantitative analysis (Image Pro Plus software, Media Cybernetics, Rockville, MD, USA) by analyzing up to 500 cells/sample from $4-5$ sections of the OFT septum spaced $24 \mu \mathrm{m}$ apart for 3 samples each of $T g f b 3^{--}$and control embryos. The percent (\%) average apoptosis from each sample was plotted using a scatter plot.

\subsection{Cell Proliferation}

Cell proliferation was monitored by immunohistochemistry. Paraffin sections of E13.5-14.5 outflow tract septal cushions from $T g f b 3^{-/-}$and wildtype embryos were subjected to immunohistochemistry with a phospho-histone H3 (Ser10) antibody (Cell Signaling Inc, \#9701, Danvers, MA, USA). Stained samples were observed with a Nikon E400 light microscope and photographs $(\times \mathrm{Obj})$ were used for quantitative analysis (Image Pro Plus software) by analyzing the number of pHH3-positive cells per sample collected from the region around fibrous OFT septum in $4-5$ sections spaced $24 \mu \mathrm{m}$ apart for 3 samples each of $T g f b 3^{-/-}$and control embryos. 


\subsection{AMIRA Three-Dimensional (3-D) Reconstruction and Volumetric Analysis}

Seven-micrometer paraffin serial sections were obtained on a microtome and stained with hematoxylin and eosin (H\&E). TIFF images of the complete aortic valves from wildtype and $T g f b 3^{-/-}$ embryos (E4.5-15.5) were captured using the $4 \times$ objective on a Nikon Optiphot-2 light microscope and loaded into the AMIRA software package (FEI Visualization Science Group, Burlington, MA, USA) [30]. All sections were aligned, and the aortic valve (left and right coronary and non-coronary leaflets) was segmented. A 3D model of the aortic valves was then generated from which the volume of the aortic valve cushion was determined for both wildtype and Tgfb3 $3^{--}$fetuses. Results were compared using a Student's t-test.

\subsection{RNAscope In Situ Hybridization}

In situ hybridization was carried out using a $T g f b 3$ RNA probe synthesized by Advanced Cell Diagnostics (Newark, CA, USA) (ACD, \#406211) [31]. Detection was done using the RNAscope 2.5 HD Duplex Reagent Mouse Kit (Cat. No 322430) according to the manufacturer's protocol (ACD). After the signal had developed, sections dehydrated in a series of ethanol and xylene were mounted using permount (Vector Lab, Burlingame, CA, USA).

\subsection{Collagen Gel Contraction Assays}

Three independent mouse embryonic fibroblast lines were generated for each wildtype and $T g f b 3$ knock out E14.5 embryos as described [32]. Mouse fibroblasts were maintained in DMEM (Invitrogen) supplemented with 10\% bovine serum, 5\% fetal calf serum and 1\% penicillin/streptomycin (Sigma-Aldrich, St. Louis, MO, USA) at $37{ }^{\circ} \mathrm{C} / 5 \% \mathrm{CO} 2$. In addition to reorganization, collagen contraction assays are indicative of the capacity for embedded cells to generate mechanical loads [33]. The capability of mouse fibroblasts to form lattices in collagen gels was assessed by plating 105 cells in $2 \mathrm{mg} / \mathrm{mL}$ collagen type-I (in $18 \mathrm{mM}$ acetic acid) prepared in complete media and supplemented with $0.1 \mathrm{M} \mathrm{NaOH}$, as detailed [34]. Free-floating collagen gels were incubated at $37^{\circ} \mathrm{C}$ for 5 days, with or without recombinant TGF $\beta 1(0.1 \mathrm{ng} / \mathrm{mL}$ or $1 \mathrm{ng} / \mathrm{mL}$, Sigma-Aldrich, St. Louis, MO). Images were acquired and best-fit shapes (circle or free form) were used to calculate the surface area of the gels using image processing utilities in Zeiss (ZEN) Imaging Software. The initial area of the collagen gel on day 1 was used to normalize across experiments. The percent (\%) decrease in gel surface area after 5 days denotes the degree of collagen contraction, with higher values indicate greater contraction [35]. The results are presented as scatter dot-plots with the box denoting the mean \pm SEM and dots representing individual data points.

\subsection{Western Blot Analysis}

Western blotting was performed with the samples of individual heart with the great vessels of the arterial pole, which were collected from wild type and Tgfb3 knockout (E18.5) fetuses. Since there was not enough protein available for Western blot analyses from individual heart at mid-gestation (E14.5), we used pooled samples (three fetal hearts and aortas/sample) from wildtype, $T g f b 3^{+/-}$ and $T g f b 3^{-/-}$fetuses at E14.5. The fetal hearts were cut into small pieces and homogenized using Wheaton tapered tissue grinders (Thermo Scientific, Rockford, IL) in M-PER mammalian protein extraction reagent (Thermo Scientific, Rockford, IL) with complete mini protease inhibitor cocktail (Sigma-Aldrich, states. Louis, MO, USA) and Halt protease and phosphatase inhibitor single-use cocktail (Thermo Scientific, Rockford, IL, USA) as per the manufacturer's protocol. Homogenized tissue lysates were subjected to brief sonication for $20 \mathrm{~s}$ on ice and kept at room temperature for $20 \mathrm{~min}$. Then, centrifugation was performed at $15,000 \mathrm{rpm}$ for $20 \mathrm{~min}$ at $4{ }^{\circ} \mathrm{C}$ and the supernatants were collected. Total protein concentration in the supernatant was determined using Pierce BCA protein assay kit (Thermo Scientific, Rockford, IL, USA) and the samples were stored at $-80^{\circ} \mathrm{C}$ until further use. For pooled samples, we collected and pooled three hearts and ascending aortas per sample after 
genotyping from wildtype, $T g f b 3^{+/-}$and $T g f b 3^{-/-}$fetuses (E14.5). Western blotting was performed with equal amounts of protein samples and the primary IgG antibodies against phospho-SMAD2 (Cell Signaling Technology, cat \#3108), SMAD2 (Cell Signaling, cat \#5339), phospho-SMAD3 (Cell Signaling, cat \#9520), SMAD3 (Cell Signaling, cat \#9523), phospho-SMAD1/5 (Cell Signaling, cat \#9516), SMAD1/5 (Cell Signaling, cat \#9743), phospho-p38 (Cell Signaling, cat \#4511), p38 (Cell Signaling, cat \#8690), phospho-ERK1/2(Cell Signaling, cat \#4370), ERK1/2 (Cell Signaling, cat \#4695) at a dilution of 1:1000. Primary IgG antibodies against all these proteins were purchased from Cell Signaling Technology, Inc. (Danvers, MA, USA). The horseradish peroxidase-conjugated anti-mouse or anti-rabbit secondary IgG antibody (Cell Signaling, cat\#7074) was used at 1:5000 dilution to detect a primary IgG antibody. In a separate Western blot, the levels of $\beta$-actin in all wildtype and Tgfb3 ${ }^{-/-}$tissue samples were determined. Western blots were incubated with Clarity Western ECL detection reagents (Bio-Rad Laboratories, USA) and exposed to X-OMAT AR films (Eastman Kodak, Rochester, NY, USA) for autoradiography. The autoradiograms were scanned on an EPSON scanner using Photoshop software (Adobe Systems, Seattle, WA, USA). $\beta$-actin, clone AC-15 monoclonal primary antibody (Sigma-Aldrich, St. Louis, MO, USA) was used as an internal housekeeping control to compare equal loading in the SDS-PAGE. Since the $\beta$-actin values were not different between the wildtype and Tgfb3-/tissue samples, the data from all blots were normalized to $\beta$-actin values obtained from an independent blot. The ratio of both phosphorylated protein/ $\beta$-actin and phosphorylated protein/total protein were plotted as scatter dot-plots with the box denoting the mean \pm SEM and dots representing individual data points.

Microsoft Excel was used for recording and managing the raw data. Data were presented as mean \pm SEM. Continuous data were presented as bar/scatter/dot plots, showing the individual data points together with the average/error bars. All data points regardless whether they were included or excluded from statistical analysis presented on scatter plots. Statistical significance was calculated using either the Student's $t$ test or the Mann-Whitney (nonparametric test) (two-tailed, for two-group comparison) using the GraphPad Prism 8 statistical program (GraphPad, San Diego, CA, USA). Exact $p$-values were calculated, and the probability values $<0.05$ were considered as significant.

\section{Results}

\subsection{Systemic Tgfb3 Deletion Disrupts Cardiac Development}

Analysis of hematoxylin and eosin (H\&E)-stained serial sections as well as muscle actin immunohistochemistry (via an anti-HHF-35 clone) of selected sections from embryonic day 13.5 to 18.5 was used to determine the cardiac pathomorphology in $T g f b 3^{-1-}$ fetuses. Cardiovascular morphology was compared between wildtype $(n=14)$ and $T g f b 3^{-/-}(n=19)$ and the cardiovascular malformations in the Tgfb3-- were determined and cataloged. Approximately two thirds cases of the $\mathrm{Tg} f \mathrm{b3}^{-/-}$fetuses developed malformations of the outflow tract and AV canal (Table 1 and Table S1). Importantly, the data revealed an abnormally smaller right ventricle than the left ventricle and that right ventricular myocardial development was impaired in about $21 \%$ cases of the $T g f b 3^{-/}$fetuses (Figure $1 \mathrm{~A}-\mathrm{C}$ and Figure S1A-C). Approximately $26 \%$ of the $T g f b 3^{-/-}$fetuses showed the myocardial defects affecting both right and left ventricles, affecting both the compact and the trabeculated myocardium (Figure 1 and Figure S1). The myocardium of the interventricular septum and apex region was very spongy and poorly formed (Figure 1 A,C and Figure S1A,C). Severely impaired myocardium of the interventricular septum was associated with the muscular type of the ventricular septal defect (VSD) in the Tgfb3 ${ }^{-/-}$fetuses (Figure $1 \mathrm{~A}, \mathrm{C}$ and Figure S1D,E). Histological analysis also revealed slightly impaired ventricular myocardium in $1 / 3$ cases of $T g f b 3^{+/-}$fetuses (E14.5) (Figure S1F,G). In situ hybridization analysis of wildtype hearts (E12.5) detected higher expression of Tgfb3 in the compact and trabecular myocardium of the right ventricle and to a lesser degree in the left ventricle (Figure 1D,E). Overall, these results indicate that TGF $\beta 3$ is required for ventricular myocardial development and that it plays a more important role in the formation of the right ventricle. 
Table 1. Summary of cases with or without cardiovascular defects in Tgfb3 knockout mice (Embryonic Day 13.5 to 18.5; $n=19$ ).

\begin{tabular}{|c|c|c|c|c|c|c|c|c|c|c|c|c|}
\hline ID\# & Genotype & Age & DORV & $\begin{array}{c}\text { AV } \\
\text { Thickening }\end{array}$ & $\begin{array}{c}\text { PV } \\
\text { Thickening }\end{array}$ & $\begin{array}{l}\text { Vascular walls } \\
\text { Abnormalities }\end{array}$ & VSD & AVSD & $\begin{array}{c}\text { Thin } \\
\text { Myocardium }\end{array}$ & $\begin{array}{c}\text { RV } \\
\text { Hyperplasia } \\
\end{array}$ & $\begin{array}{c}\text { MV } \\
\text { Thickening }\end{array}$ & $\begin{array}{c}\text { TV } \\
\text { Thickening }\end{array}$ \\
\hline KO1 & $T g f b 3^{-/-}$ & e16.5-17.5 & No & No & No & No & No & No & No & No & No & No \\
\hline $\mathrm{KO} 2$ & Tgfb3 $3^{-/-}$ & e13.5 & No & Yes & Yes & No & Perimembranous & No & Yes & No & Yes & Yes \\
\hline KO3 & Tgfb3-l- & e14.5-15.5 & No & No & No & No & No & No & No & No & Yes & Yes \\
\hline KO4 & $T g f b 3^{-1-}$ & e14.5-15.5 & No & Yes & Yes & No & Muscular & No & No & No & Yes & Yes \\
\hline KO5 & Tgfb3 $3^{-/-}$ & e14.5-15.5 & No & Yes & Yes & No & Muscular & No & Yes & No & No & No \\
\hline KO6 & Tgfb3 $3^{-/-}$ & e14.5-15.5 & No & No & No & No & No & No & No & No & No & No \\
\hline KO7 & $T g f b 3^{-1-}$ & e14.5-15.5 & No & No & No & No & No & No & No & No & No & No \\
\hline KO8 & $T g f b 3^{-/-}$ & e16.5-17.5 & No & No & No & No & No & No & No & No & No & No \\
\hline KO9 & $T g f b 3^{-/-}$ & e13.5 & No & Yes & Yes & No & Perimembranous & No & No & Yes & Yes & Yes \\
\hline KO10 & $T g f b 3^{-1-}$ & e16.5-17.5 & No & Yes & Yes & No & No & No & No & No & No & No \\
\hline KO11 & $T g f b 3^{-1-}$ & e14.5-15.5 & No & Yes & Yes & ND & No & No & No & Yes & Yes & Yes \\
\hline KO12 & $T g f b 3^{-/-}$ & e18.5 & No & Yes & Yes & Yes & No & No & Yes & No & No & No \\
\hline KO13 & Tgfb3-/- & e18.5 & No & Yes & Yes & Yes & Perimembranous & No & No & Yes & No & No \\
\hline KO14 & Tgfb3 $3^{-/-}$ & e15.5-16.5 & No & Yes & Yes & No & No & No & Yes & No & No & No \\
\hline KO15 & Tgfb3 $3^{-/-}$ & e15.5-16.5 & Subaortic & Yes & Yes & Yes & Perimembranous & No & No & Yes & Yes & Yes \\
\hline KO16 & $T g f b 3^{-/-}$ & E18.5 & No & No & No & No & No & No & No & No & No & No \\
\hline KO17 & Tgfb3-/- & e13.5 & No & Yes & Yes & No & No & No & No & No & Yes & Yes \\
\hline KO18 & $T g f b 3^{-/-}$ & e14.5 & No & No & No & No & No & No & No & No & No & No \\
\hline \multirow[t]{2}{*}{ KO19 } & $T g f b 3^{-/-}$ & e13.5 & No & Yes & Yes & No & Muscular & No & Yes & No & Yes & Yes \\
\hline & $\begin{array}{c}\text { Number } \\
\text { of cases } \\
(\%)\end{array}$ & & $1(5.2 \%)$ & $12(63.15 \%)$ & $12(63.15 \%)$ & $3(15.7 \%)$ & $\begin{array}{c}\mathrm{P}: 4 \text { (21\%); M: } 3 \\
(15.7 \%)\end{array}$ & $0(0 \%)$ & $6(31.5 \%)$ & $4(21 \%)$ & $8(42.1 \%)$ & $8(42.1 \%)$ \\
\hline $\begin{array}{l}\text { Total } \\
\text { cases }\end{array}$ & $T g f b 3^{-/-}$ & 19 & & & & & & & & & & \\
\hline $\begin{array}{l}\text { Total } \\
\text { cases }\end{array}$ & $\begin{array}{l}\text { Wildtype } \\
\left(\mathrm{T} g f b 3^{+/+}\right)\end{array}$ & 14 & & & & & & & & & & \\
\hline
\end{tabular}

Abbreviations: DORV, double outlet right ven 


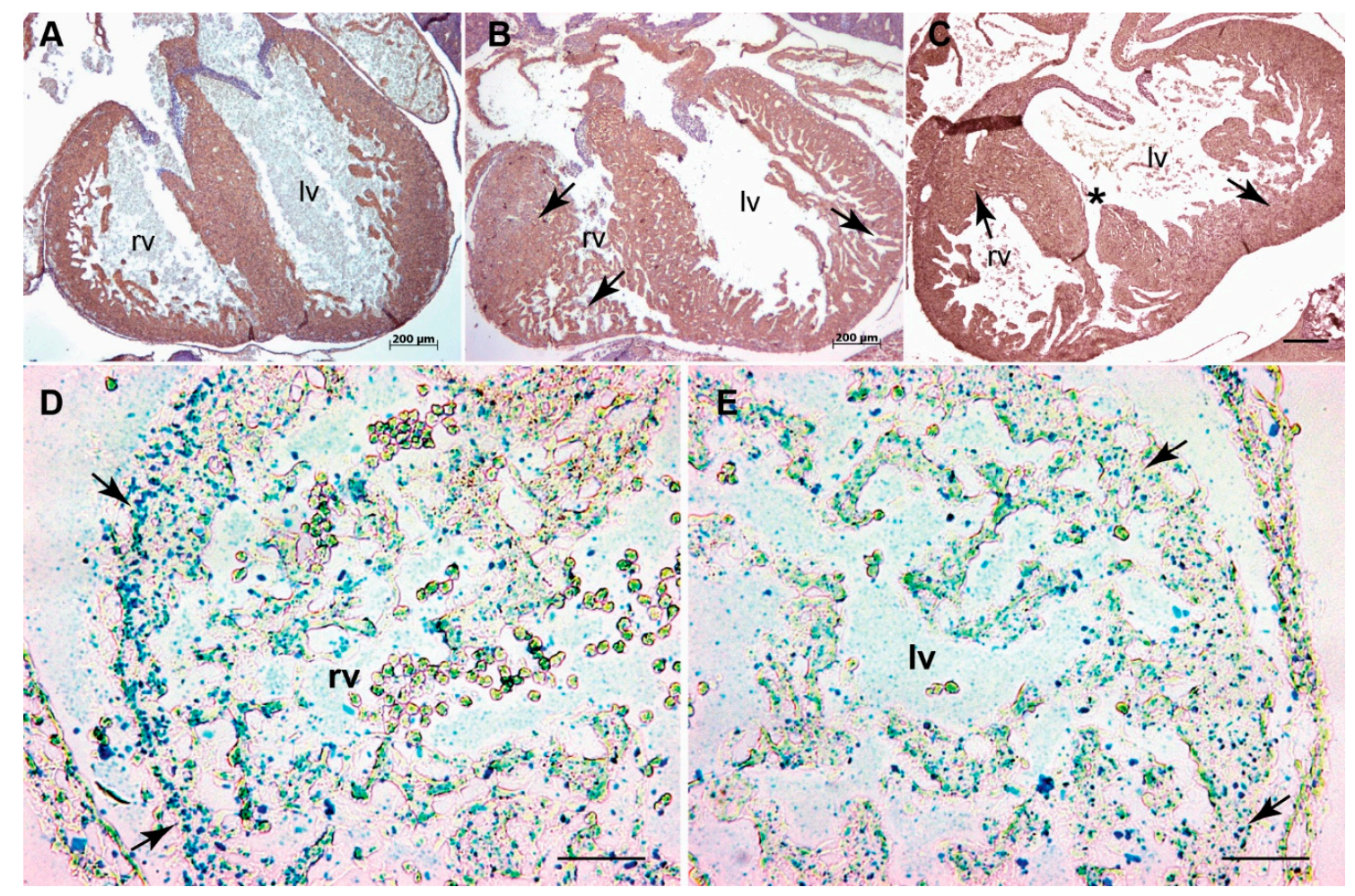

Figure 1. $T g f b 3$ deletion leads to an impaired myocardium in mouse embryos. (A-C), Cross- sections of E15.5-16.5 fetuses showing cardiac muscle actin (clone HHF35) immunohistochemistry for wildtype (A) and two different TGF $\beta 3$-deficient fetuses (B,C). TGF $\beta 3$-deficient fetuses developed non-uniform right ventricular myocardium with heterogeneous regions of thicker (B, left arrow) and thinner (B, bottom arrow) myocardium and spongy (B, right arrow) and thicker (C, right arrow) left ventricular myocardium compared to the wildtype littermate fetus (A), Other mutant fetus had a muscular ventricular septal defect (VSD) $(\mathbf{C}$, asterisk) $(n=6)$. (D,E), Representative images revealed $T g f b 3$ expression (green-blue punctate dots, arrows) in the compact and trabecular myocardium of the right (D) and left ventricles (E) from wildtype E12.5 embryo. Scale bars $=200 \mu \mathrm{m}$ for (A-C), $50 \mu \mathrm{m}$ for (D,E). Abbreviations: rv, right ventricle; lv, left ventricle.

\subsection{Tgfb3 Deletion Leads to Outflow Tract Cushion Remodeling and Septal Defects}

Histological examination of the H\&E stained serial sections from wildtype and Tgfb3 ${ }^{-1-}$ fetuses at E13.5-18.5 revealed that about two thirds of the cases of the homozygous mutant fetuses developed various cardiac outflow tract malformations with variable penetrance (Table 1 and Table S1). Cardiac muscle immunohistochemistry (via anti-cardiac muscle actin) was performed to confirm the OFT malformations. Major cardiac OFT malformations included double-outlet right ventricle (DORV) and a large OFT ventricular septal defect (VSD) with extension into inflow (about 5\% cases) (Figure 2A-D), thickening of the pulmonary and aortic valve (about two thirds of cases) (Figure 3A-E and Figure S2A-D), abnormal ascending aortic and pulmonary trunk walls (about 16\% cases) (Figure 3A,B and Figure S3). The DORV was mainly subaortic in nature and exhibited defective fusion and remodeling of the RV OFT septum (Figure 2A,B and Figure 3C-E). The walls of the aorta and pulmonary trunk appeared morphologically immature and the vascular smooth muscle cells distributed randomly in the vascular walls of $T g f b 3^{-/}$fetuses compared to their control littermates (Figure 3A,B and Figure S3). In addition, histological analysis also revealed hypoplastic vascular walls of aorta and/or pulmonary trunk and mildly thickened aortic and/or pulmonary valves in one third of cases of $\mathrm{Tg}_{\mathrm{fb}} \mathrm{B}^{+/-}$fetuses (E14.5) (Figure S2A,B,D,E). There These OFT defects were consistent with the significant expression of $T g f b 3$ in OFT cushion mesenchyme and walls of aorta and pulmonary trunk (Figure 3F). Morphometric comparison and volume measurements via AMIRA 3D reconstruction of serial sections 
confirmed the hyperplastic nature of the OFT cushions in $T g f b 3^{-/-}$fetuses compared to the wildtype littermate fetuses (Figure S4). Since the OFT septum was abnormal in Tgfb3 $3^{-/}$embryos, TUNEL assay was used to quantify the apoptosis. The OFT septum consists of two cell populations-cardiac neural crest (NCC) and second heart field (SHF)-derived cells. Apoptosis is a phenomenon of NCC [36]. RNAscope in situ hybridization confirmed that $T g f b 3$ is significantly expressed in the OFT septum. Apoptosis centrally in the OFT septum (Figure 3G-I) could activate TGF $\beta 3$ in the circle of SHF-derived cells around it for their proper differentiation and proliferation (Figure 3J-L). To get the measurements of the difference in apoptosis between wildtype and Tg $f b^{-/-}$embryos the number of cells (as indicated in Figure 3I) were counted within the central NCC bound area. TUNEL analysis showed that the apoptosis of cushion mesenchymal cells at the OFT septum was significantly decreased in the affected $T g f b 3^{-/}$fetuses compared to wildtype littermates (Figure 3G-I). Immunohistochemical analysis via anti-phospho-histone H3 (Ser10) revealed an increase in the myocardial cell proliferation surrounding the central fibrous OFT septum and in the right ventricular myocardium (Figure 3J-L). This indicates that TGF $\beta 3$ is required for cardiac apoptosis and proliferation, which are important to cushion mesenchymal differentiation and maturation. Collectively, the data indicate that the loss of $T g f b 3$ affects cardiac outflow tract cushion remodeling and septal and alignment processes.

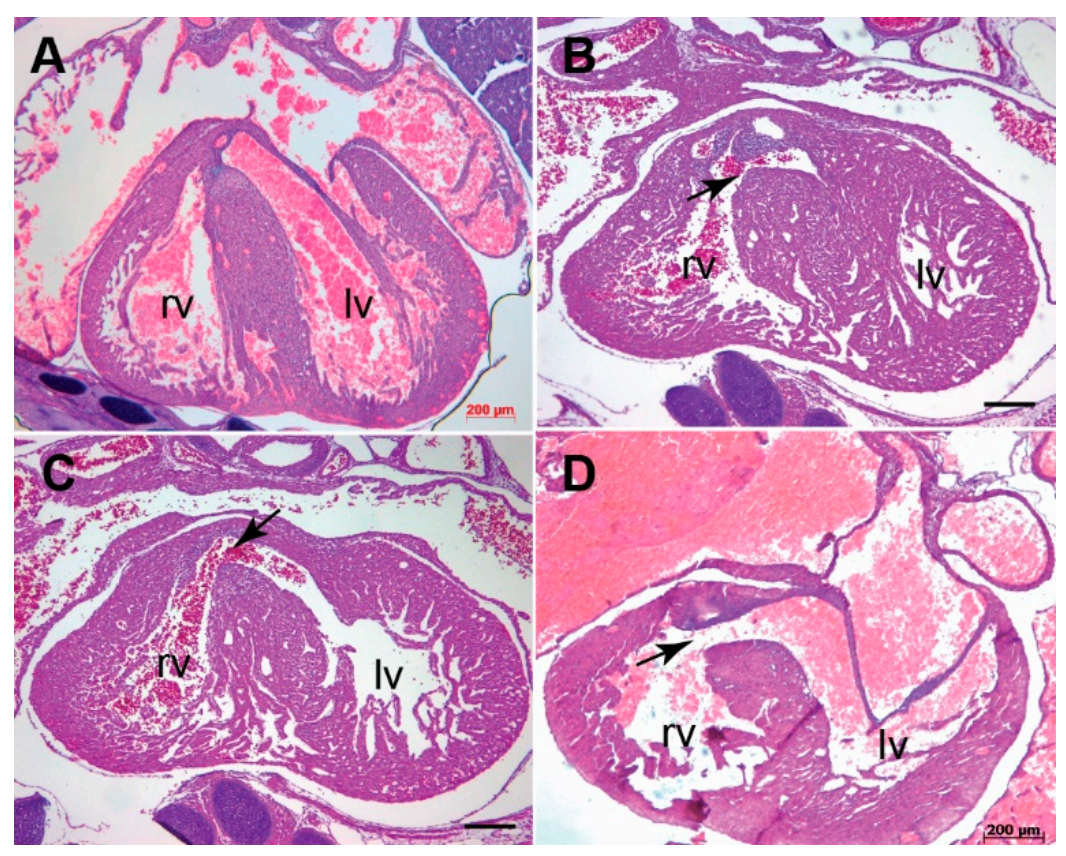

Figure 2. $T g f b 3$ knockout mouse fetuses exhibit outflow tract septal and alignment defects. (A-D), Hematoxylin and eosin staining of hearts for E15.5-16.5 wildtype (A) and two different $T g f b 3^{-/-}$fetuses (B-D). $T g f b 3^{-1-}$ fetuses develop both double-outlet right ventricle (B, arrow) and perimembranous ventricular septal defect (C,D; arrows). Scale bars $=200 \mu \mathrm{m}$ for $(\mathbf{A}-\mathbf{D})$. Abbreviations: rv, right ventricle; lv, left ventricle. 


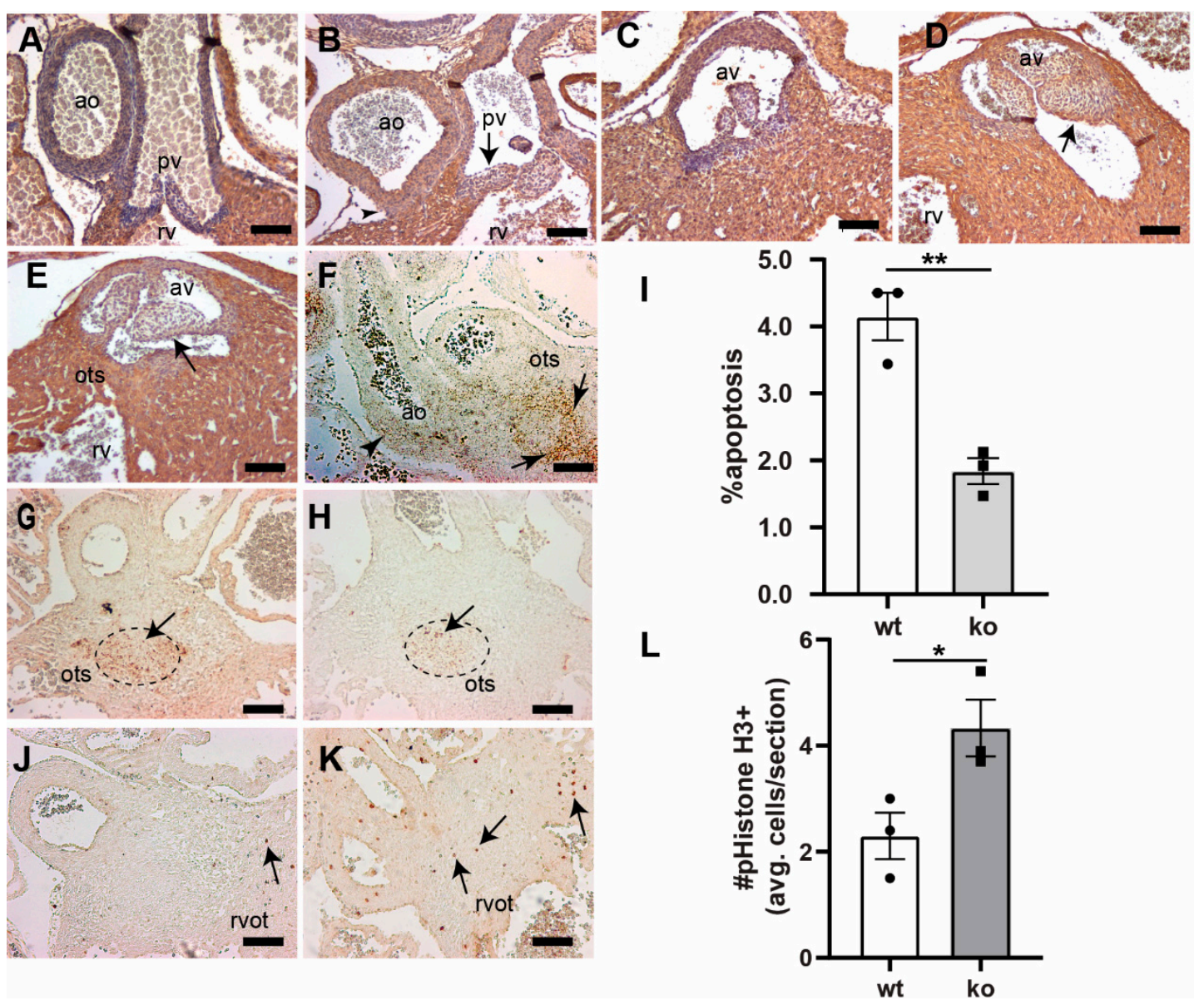

Figure 3. Loss of $T g f b 3$ in mice results in the outflow tract cushion and vascular wall defects. (A-E), Cross-sections of E15.5-16.5 fetuses showing cardiac muscle actin (clone HHF35) immunohistochemistry for wildtype controls (A,C) and TGF 33 -deficient fetuses (B,D,E). Tgfb3 ${ }^{-/-}$fetuses develop dysmorphic pulmonary (B) and aortic valve (D,E), and abnormal ascending aortic and pulmonary trunk walls (B) morphology. $T g f b 3^{-/-}$fetuses also demonstrating hypoplastic outlet septum (E). (F) Representative image of a wildtype embryo (E11.5) using RNAscope in situ hybridization reveals Tgfb3 expression (brown punctate dots) in the vascular wall (arrowhead) and outflow tract septum (arrow). $(\mathbf{G}, \mathbf{H})$, Apoptosis (E13.5) using TUNEL staining (brown colored nuclei) in outflow tract septum mesenchyme. Compared to wildtype controls $(\mathrm{G}), \mathrm{Tg} f b 3^{-/-}$OFT septum have a reduced number of apoptotic cells (H). (I) Quantification of fraction of cells undergoing apoptosis. Mean \pm SEM of \% average apoptosis from at least 4 sections for each sample was used for comparison. Quantification was predominantly done in the area of outflow tract septum marked by a dotted circle. Reduced apoptosis in Tgfb3 ${ }^{-1-}$ hearts was noted as compared to wildtype embryos ( ${ }^{* *} p=0.004$, Student's $t$ test; $p=0.07$, Nonparametric (Mann Whitney test)). (J-L), Cell proliferation (E13.5) using phospho-histone H3 (Ser10) immunohistochemistry. Mean \pm SEM of average pHistoneH3+ cells/section from at least 4 sections for each sample was used for comparison. Quantification was mainly restricted to the region around the fibrous outflow tract septum (L). Increased cell proliferation in Tgfb3 ${ }^{-1}$ hearts (K, arrows) was observed as compared to wildtype (J) embryos $\left({ }^{*} p=0.04\right.$, Student's $t$ test; $p>0.05$, Nonparametric (Mann Whitney test)). Scale bars $=100 \mu \mathrm{m}$ for $(\mathbf{A}-\mathbf{E}, \mathbf{F}-\mathbf{H}, \mathbf{J}, \mathbf{K})$. Abbreviations: rv, right ventricle; av, aortic valve; pv, pulmonary valve; ao, ascending aorta; ots, outlet septum, rvot, right ventricular OFT. 


\subsection{Tgfb3 Deletion Leads to AV Cushion Remodeling Defects}

Analysis of H\&E stained serial sections revealed that approximately $42 \%$ cases of $T g f b 3^{-1-}$ fetuses developed malformations of the AV valves (Table 1 and Table S1). Mitral and/or tricuspid valve thickening was observed in all affected cases of the overall mutants analyzed (Figure 4A-D). Importantly, a significant proportion of the Tgfb3 ${ }^{-/}$fetuses developed VSD, which included perimembranous VSD (about $21 \%$ cases) (Figure 2A,C,D). The perimembranous VSD is normally linked to OFT VSD with an extension into the inlet septum and that it not obligatory related to abnormal AV valves. Thus, the perimembranous VSD is due to abnormal OFT cushion remodeling and is not related to AV cushion remodeling defects. Histological analysis did not reveal the presence of any AV septal defect (AVSD) in Tgfb3 ${ }^{-/-}$embryos. These data indicate a requirement of TGF $\beta 3$ in the AV cushion remodeling and but not in $\mathrm{AV}$ septal formation during heart development.

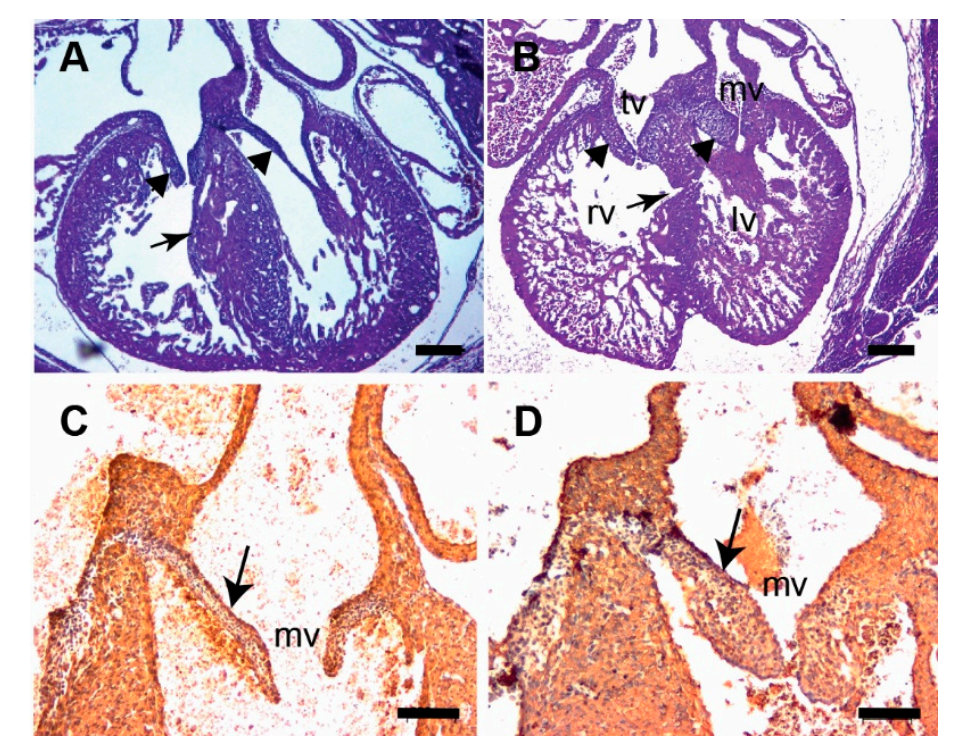

Figure 4. $T g f b 3$ knockout fetuses exhibit atrioventricular valve thickening. (A,B) H\&E stained sections of wildtype (A) and Tgfb3 ${ }^{-/-}$fetus (E14.5-15.5) showing mitral valve and tricuspid valve thickening (B, arrowheads). Note that the ventricular myocardium is thin and abnormal with muscular ventricular septal defect in $\mathrm{Tgfb3}^{-/-}$(B, arrow). (C,D), Cardiac muscle actin (clone HHF35) immunohistochemistry of cross-sections of E15.5-16.5 wildtype (C) and Tgfb3 ${ }^{-/-}$(D) fetuses. Tgfb3-/- fetus develop thickened mitral valves $(\mathbf{D}$, arrow). Scale bars $=200 \mu \mathrm{m}$ for $(\mathbf{A}, \mathbf{B}), 50 \mu \mathrm{m}$ for $(\mathbf{C}, \mathbf{D})$. Abbreviations: rv, right ventricle; lv, left ventricle; $\mathrm{tv}$, tricuspid valve; $\mathrm{mv}$, mitral valve.

\subsection{TGF 33 Is Required for Extracellular Matrix Reorganization}

Given the involvement of TGFB3 in the development of fibrofatty lesions in the ARVD1, TGF $\beta 3$-deficient whole mouse embryonic fibroblasts were generated and tested for their ability to reorganize collagen in vitro in a three-dimensional collagen lattice formation assay. TGF $\beta 3$-deficient and wildtype fibroblasts were seeded in collagen gels and cultured for five days with or without $0.1 \mathrm{ng} / \mathrm{mL}$ and $1 \mathrm{ng} / \mathrm{mL}$ TGF $\beta 1$. The degree of collagen contraction (i.e., decrease in the surface area of the collagen gel) over time was determined. The wild type fibroblasts contracted in response to exogenously added TGF $\beta 1$, as expected, in a dose-dependent fashion. TGF $\beta 3$-deficient fibroblasts exhibited a reduced contraction compared to the wild type. Nonetheless, they remained responsive to TGF $\beta 1$ induction (Figure 5A-E). The difference in the degree of contraction between TGF 33 -deficient and wildtype whole mouse embryonic fibroblasts was rescued by exogenously added TGF $\beta 1$, indicating that the excess TGF $\beta 1$ is able to rescue the impaired ability of TGF $\beta 3$-deficient whole mouse embryonic fibroblasts to reorganize collagen lattices. 

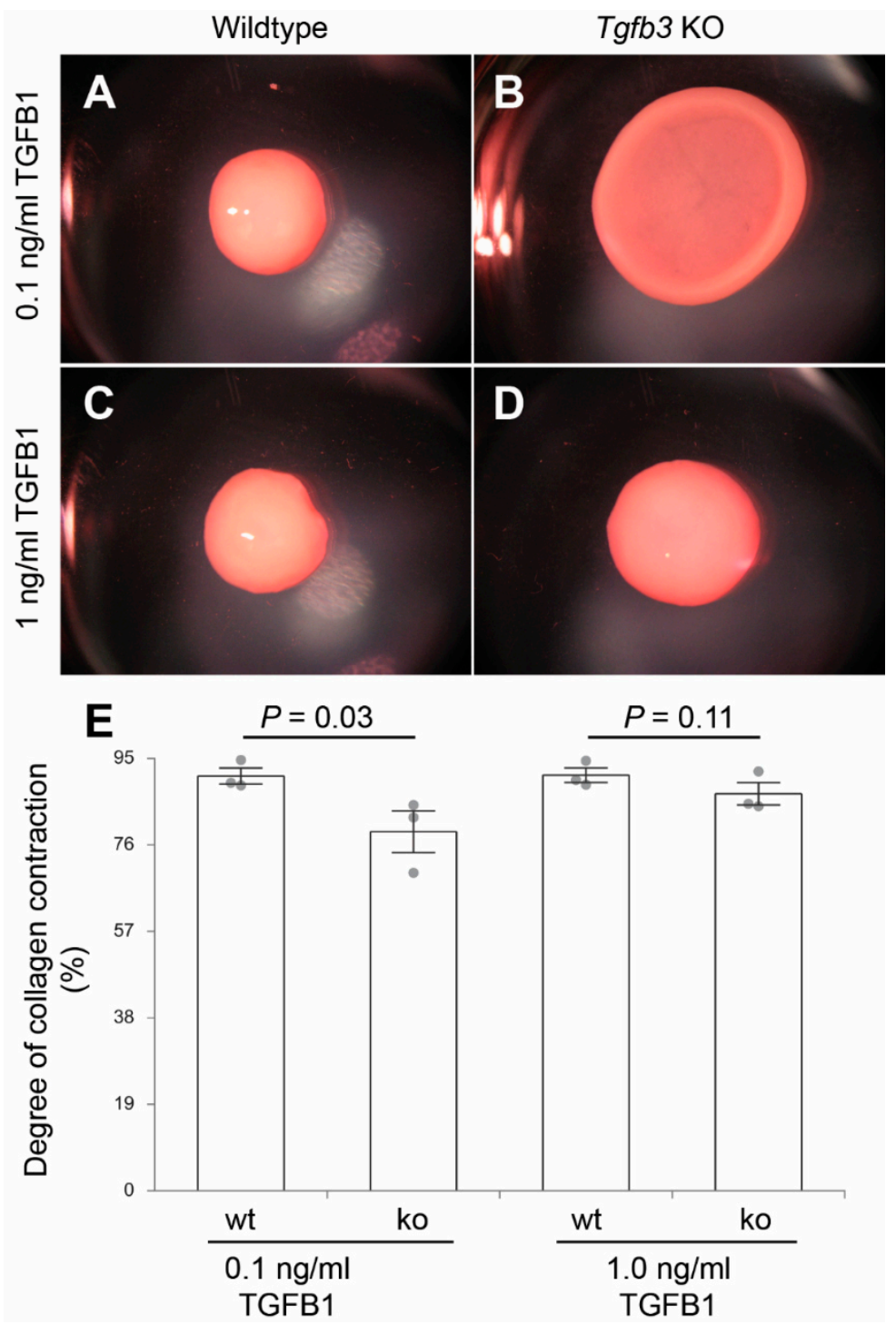

Figure 5. Collagen lattice formation assay. (A-D), dissecting microscope images of fibroblast-laden collagen gels after 5 -days using three independent fibroblast cell lines $(n=3)$ from wildtype $(\mathbf{A}, \mathbf{C})$ or Tgfb3 ${ }^{-1}$ embryos (B,D) in the presence of low $(0.1 \mathrm{ng} / \mathrm{mL})(\mathbf{A}, \mathbf{B})$ and high $(1 \mathrm{ng} / \mathrm{mL})(\mathbf{C}, \mathbf{D})$ doses of exogenous recombinant TGFB1. TGF 33 -deficient whole mouse embryonic fibroblasts treated with the low dose of exogenous TGFB1 have decreased contractility compared to the wildtype fibroblasts while higher doses rescue contractility and lattice formation (E). $p$-Values are indicated in the histogram. Numerical data are presented as scatter dot-plots with the box denoting the mean; error bars identify the SEM.

\subsection{Tgfb3 Deletion Leads to Hyper-Activated SMAD2/3 and SMAD1/5 Signaling Pathways}

To determine the role of TGF $\beta 3$ in the regulation of downstream SMADs, the activation of important downstream TGF $\beta$-dependent SMADs in isolated whole hearts with attached ascending aorta from the wildtype $(n=6)$ and Tgfb3 ${ }^{--}(n=6)$ fetuses (E18.5) was determined by Western blot analysis. The changes in the TGF $\beta$ receptor-dependent phosphorylation of serine/threonine residues of SMADs (i.e., pSMAD2), SMAD3 (i.e., pSMAD3), and SMAD1/5 (i.e., pSMAD1/5) were quantified via densitometric analysis from the Western blots. There was no significant change in the total amount of the SMAD2, SMAD3, SMAD1/5, and $\beta$-actin proteins in the Tgfb3 $3^{-/-}$hearts compared to wildtype hearts (Figure 6A-C). Importantly, these biochemical data showed that the levels of pSMAD2, pSMAD3, and pSMAD1/5 were significantly increased in the hearts of the Tgfb3 $3^{-1-}$ fetuses compared to the wildtype fetuses (Figure $6 \mathrm{~A}-\mathrm{C}$ ). We found that $2 / 3$ cases of mutants fall within a high SMAD-dependent 
TGF $\beta$ signaling cluster, whereas the levels of activated SMADs were not significantly altered in one third of cases of $\mathrm{Tg}_{\mathrm{fb}} \mathrm{3}^{-/-}$fetuses compared to wildtype fetuses. Biochemical analysis of 'pooled' tissue samples (three hearts with ascending aortas/sample) confirmed elevated pSMAD2 in Tgfb3 ${ }^{-/-}$ fetuses and also revealed increased pSMAD2 in Tgfb3 ${ }^{+/-}$fetuses compared to wildtype fetuses at E14.5 (Figure 6E). Importantly, pSMAD2 levels were higher in Tgfb3 $3^{--}$fetuses than the $\mathrm{Tg}_{\mathrm{fb}} \mathrm{3}^{+-}$fetuses, suggesting that loss of Tgfb3 in a dose-dependent fashion triggers SMAD2 activation. Taken together, heterozygous or homozygous loss-of-function of $T g f b 3$ results in paradoxically increased levels of activated SMAD2, SMAD3, and SMAD1/5 in the fetal cardiovascular tissues.

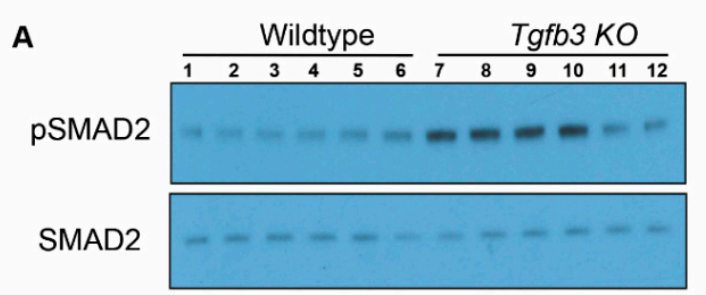

B

pSMAD3

SMAD3

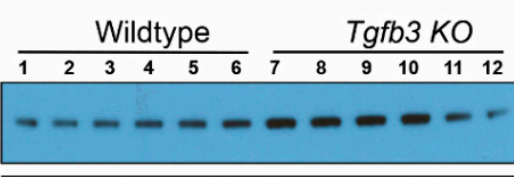

C

pSMAD $1 / 5$

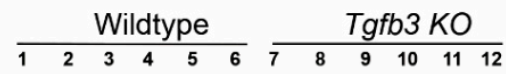

SMAD $1 / 5$

D

$\beta$-Actin
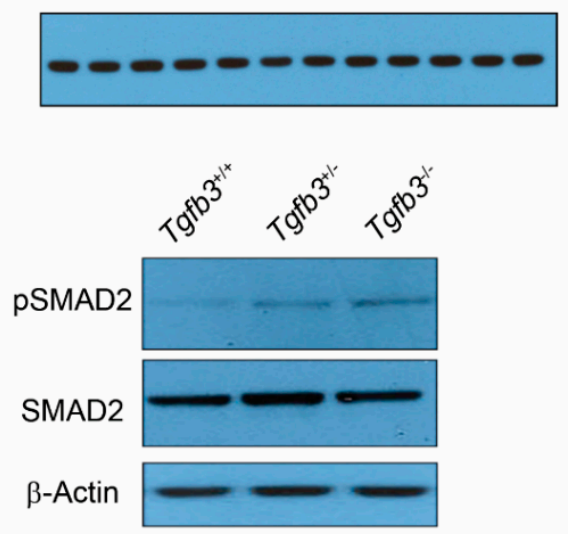
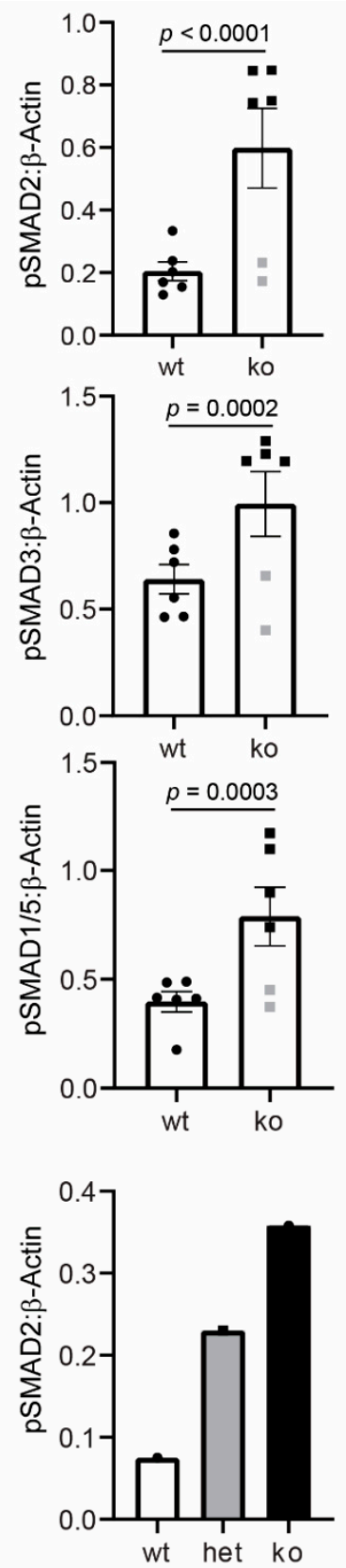
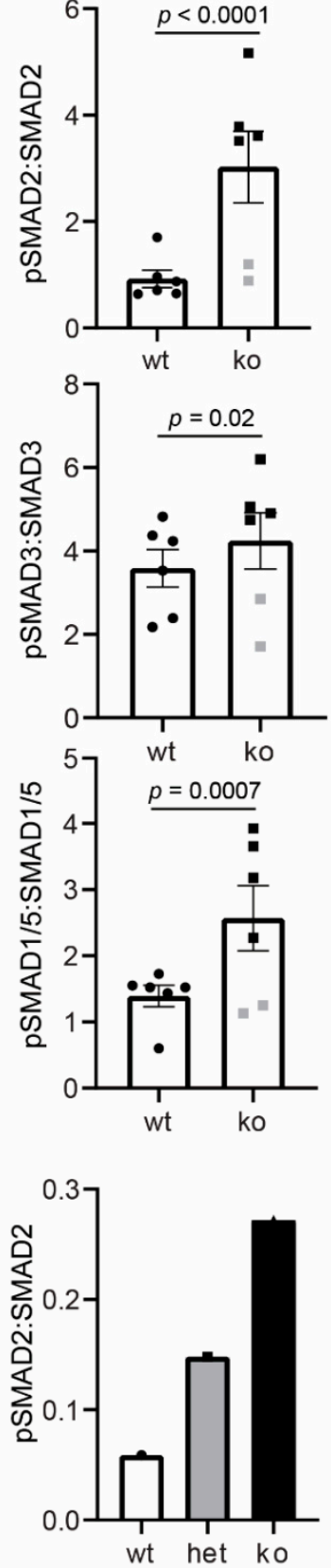

Figure 6. TGF $\beta 3$ is required for TGF $\beta-S M A D$ cardiovascular pathway activation. (A-C), Western blot analysis of fetal hearts and the accompanied ascending aorta (E18.5) shows protein levels of the phosphorylated SMADs (pSMAD2, pSMAD3, pSMAD1/5) and total SMADs (SMAD2, SMAD3, SMAD1/5). 
SMAD1/5). (D) A common and independent $\beta$-actin blot (C, bottom) was used for normalizing data from pSMAD2, pSMAD3, and pSMAD1/5 blots. There was no difference in the $\beta$-actin levels between any cardiovascular tissues taken from wildtype and $\mathrm{Tgfb}^{-/-}$mice. Densitometric quantification of phosphorylated proteins after normalization to $\beta$-actin and total non-phosphorylated proteins is shown on the right (A-C). E, Representative western blots of pooled samples (3 hearts and aortas/sample) from wildtype, $T g f b 3^{+/-}$, and Tgfb3 ${ }^{-/-}$fetuses (E14.5) for pSMAD2, SMAD2, and $\beta$-actin. Each western blot was repeated three times with similar results. Western blots and densitometric quantification show the levels of pSMAD2 (60 kDa) and SMAD2 (60 kDa) (A,D), pSMAD3 (52 kDa) and SMAD3 (52 kDa) (B), pSMAD1/5 (60 kDa) and SMAD1/5 (60 kDa) (C), and $\beta$-actin (42 kDa) (A-D). Note that levels of pSMAD2, pSMAD3, and pSMAD1/5 are increased in individual samples taken from TGF $\beta 3$-deficient mice (A-C). The levels of pSMAD2 were also higher in pooled samples of both $T g f b 3^{+/-}$and $T g f b 3^{-/-}$fetuses compared to pooled sample from wildtype fetuses. Tgfb3 ${ }^{-/-}$had slightly higher levels of pSMAD2 than the Tgfb3 ${ }^{+/-}$ fetuses. Data points excluded from statistical analysis (Student's $t$ test) are indicated by grey symbols (A-C). Individual densitometric values from each pooled samples were plotted (E). All western blots (A-C) with individual samples were done in triplicate. Thus, all data points represent an average values of three independent blots (A-C). $p$-values are shown in the figure. Numerical data from multiple individual samples are presented as scatter dot-plots with boxes denoting the mean; error bars indicate the SEM.

\subsection{TGF $\beta 3$-Deficiency Triggers Activation of Non-Canonical MAPK-Mediated TGF $\beta$ Signaling Pathways}

TGF $\beta$ signaling under pathophysiological conditions can occur via non-SMAD pathways, including p38 MAPK and ERK1/2 MAPK [23]. Consequently, Western blot analysis was done on wildtype $(n=6)$ and $T g f b 3^{-/-}(n=6)$ whole individual hearts with ascending aorta to determine the changes in the downstream components of the non-canonical TGF $\beta$ pathway. The densitometric analysis found no change in the levels of $\beta$-actin and total p38 protein (Figure 7A). Importantly, the data revealed significantly increased activation of p38 MAPK (i.e., pp38 MAPK) in the Tgfb3 ${ }^{-1-}$ hearts and aorta compared to the wildtype (Figure 7A). Moreover, the data showed that levels of activated ERK1/2 MAPK (i.e., pERK1/2), when normalized to total ERK1/2, were also higher in the cardiovascular tissues of the $T g \mathrm{fb3}^{-/-}$fetuses than the wildtype (Figure 7B). Finally, Western blot analysis of pooled cardiovascular tissue samples (three hearts and aortas/sample) not only confirmed the elevated levels of pp38 and pERK1/2 in Tgfb3-- fetuses but they also revealed increased levels of pp38 and pERK1/2 in $\mathrm{Tgfb}^{+/-}$fetuses compared to wildtype fetuses (Figure 7C). Additionally, pp38 and pERK1/2 levels were higher in $T g f b 3^{-/-}$fetuses than the Tgfb3 ${ }^{+/-}$fetuses, suggesting that loss of $T g f b 3$ in a dose-dependent fashion triggers the activation of both pp38 and pERK1/2 MAPKs. Collectively, these findings indicate that heterozygous or homozygous loss of $T g f b 3$ in vivo leads to hyper-activation of SMAD-independent non-canonical TGF $\beta$ signaling through $\mathrm{p} 38$ MAPK and ERK1/2 MAPK pathways. 
A

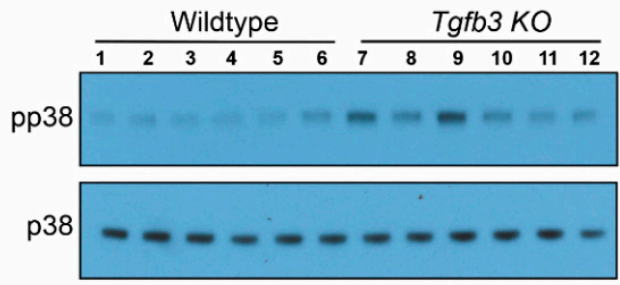

B

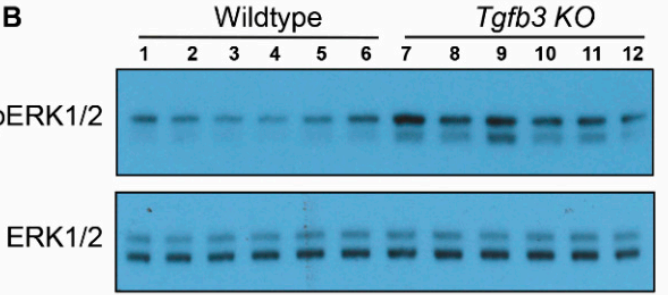

C

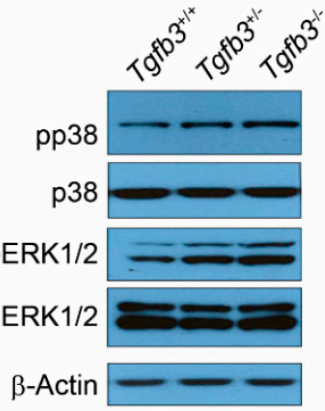

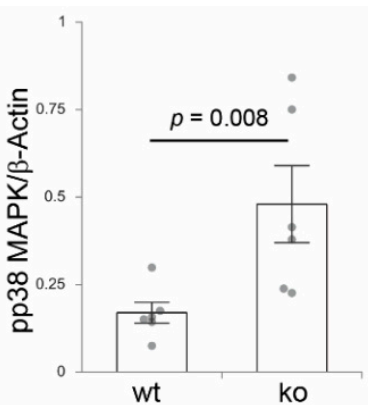
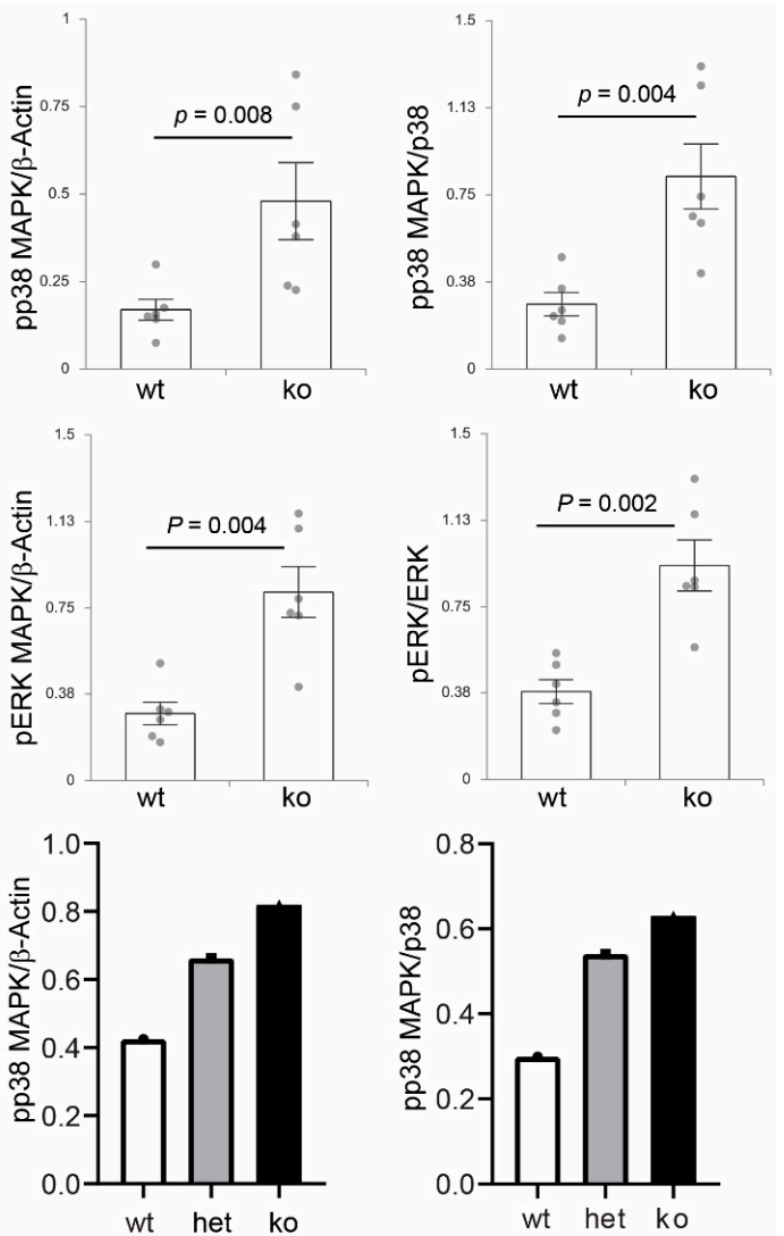

Figure 7. TGF $\beta 3$ is required for SMAD-independent non-canonical TGF $\beta$ cardiovascular pathway activation. (A,B) Western blot analysis of fetal hearts and accompanying ascending aortas (E18.5) show protein levels of phosphorylated p38 MAPK (pp38), total p38 MAPK (p38), phosphorylated ERK1/2 MAPK (pERK1/2), and total ERK1/2 MAPK (ERK1/2). Densitometric quantification of phosphorylated proteins after normalization to $\beta$-actin (via a common $\beta$-actin blot used in Figure 6D) and total non-phosphorylated proteins is shown on the right $(\mathbf{A}, \mathbf{B})$. Western blots and densitometric quantification show levels of pp38 (43 kDa) and p38 (40 kDa) (A), pERK1/2 (44/42 kDa) and ERK1/2 (44/42 kDa) $(\mathbf{A}, \mathbf{B})$. Note that similar results are obtained with normalization to either $\beta$-actin or the respective total p38 and ERK1/2 proteins. Note also that levels of pp38 MAPK and pERK1/2 MAPK are significantly increased in TGFß3-deficient cardiovascular tissues. No data points were excluded from statistical analysis. Nonparametric test (Mann Whitney test) was used for analysis. $p$-values are shown in the figure. Numerical data are presented as scatter dot-plots with boxes denoting the mean; error bars indicate the SEM. (C) Representative western blots of pooled samples (3 hearts and aortas/sample for each genotype) showing elevated levels of pp38 and pERK1/2 in Tgfb3 ${ }^{+-}$and Tgfb3 ${ }^{-/-}$fetuses (E14.5). Each western blot was repeated three times with similar results. Individual values for each samples were plotted. Notably, there is a trend of higher levels of both pp38 and pERK1/2 in Tgfb3-/- fetal hearts compared to $T g f b 3^{+/-}$fetuses.

\section{Discussion}

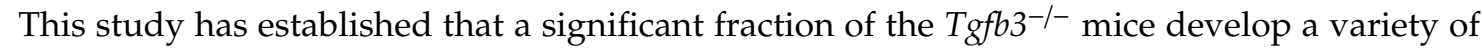
cardiovascular malformations including DORV, ventricular septal defects (OFT, perimembranous, muscular), abnormal vascular walls, aortic valve and $\mathrm{AV}$ valve thickening, and impaired ventricular

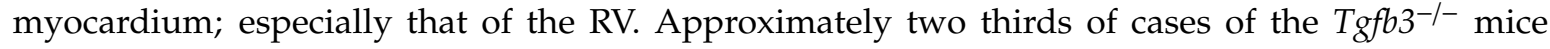
develop one or more cardiovascular malformations and these phenotypic differences are not due to the 
genetic background of these mice since all mice used in this study are on the C57BL/6 background produced via non-sibs mating. In addition, $\mathrm{Tg}_{\mathrm{f}} \mathrm{3}^{+/-}$fetuses develop mild cardiovascular malformations, including hypoplastic arterial walls, OFT cushion thickening, and impaired ventricular myocardium. These findings are consistent with the gene expression studies reported here and previous studies showing strong Tgfb3 expression in the developing heart [26]. Two studies, in particular, established that systemic deletion of $T g f b 3$ in mice leads to a cleft palate and perinatal lethality [1,2]. Tgfb3 ${ }^{-/-}$mice (one third of cases), which do not have any obvious cardiovascular structural defects, still die perinatally and have a cleft palate. Tgfb3 heterozygous mice survive normally. Many mutations in mice that cause a cleft palate also lead to heart defects [37]. TGFB3 mutations in the LDS5 (also known as RNHF syndrome) typically cause cleft palate and is also characterized by several cardiovascular malformations, including thoracic and/or abdominal aneurysms, persistent foramen ovale, atrial or ventricular septal defects, atrioventricular block, aortic and mitral valve disease, and familial arrhythmogenic right ventricular dysplasia (ARVD1/C) involving replacement of the ventricular myocardium with fatty and fibrous elements, preferentially in the free wall of the right ventricle $[9,12,13,38]$. It is interesting that $T g f b 3^{-/-}$fetuses have no atrial septal defects (ASD) and inflow tract abnormalities such as atrioventricular septal defects (AVSD), double inlet left ventricle (DILV), and common AV canal. This would indicate that abnormal OFT remodeling such as related to NCC and anterior SHF may be involved in OFT-related defects of $T g f b 3^{-/-}$embryos. Overall, the data presented in this study is consistent with clinical genetic findings and indicate that TGF $\beta 3$ is required for multiple important aspects of cardiovascular development.

$T g f b 3$ is expressed in post-EMT cushion mesenchyme during cushion remodeling and differentiation, which is consistent with the OFT and AV cushion remodeling and OFT septation defects in Tgfb3 $3^{--}$embryos. This is a contrast with the Tgfb2-/- embryos which develop both OFT and AV septation defects [39]. The data is also in line with previous studies indicating that TGF $\beta 3$ is not expressed in the mouse heart during EMT and that the cardiac EMT is not affected in Tgfb3-/embryos [40,41]. TGF $\beta$ s are known to induce apoptosis [42-44]. As a consequence, the effect of absence of TGF $\beta 3$ might result in down-regulated apoptosis, as shown here. Therefore, it is unlikely that down-regulated TGF $\beta 3$ represses apoptosis. Furthermore, latent TGF $\beta 3$, as demonstrated in the SHF [45] needs to be activated and apoptotic neural crest cells, by changing the micro-environment, might just activate TGF $\beta$ s. Definitive proof that this chain of events is reversed involves experiments inhibiting apoptosis by deleting, e.g., apoptosis-specific genes as performed by Watanabe and Fisher [46] in the chicken embryo, which included outflow tract malformations even though the focus was not on TGF $\beta$ signaling. In addition, cell lineage tracing superimposed on systemic or conditional $T g f b 3$ null embryos will be another approach to reveal the effect of $T g f b 3$ on cellular apoptosis in the OFT septum. Collectively, the OFT cushion remodeling defects are consistent with the presence of both aortic and pulmonary valve thickening in the Tgfb3 $3^{--}$fetuses. OFT septal malformations such as the DORV, are mainly subaortic in nature and exhibit defective fusion and remodeling of the outlet septum in Tgfb3-/embryos. In some of the Tgfb3 ${ }^{-/-}$fetuses, the aorta was positioned directly over a VSD due to an OFT alignment defect, which might be the result of abnormal inner curvature remodeling. On the other hand, the AV cushion remodeling defects are involved in the thickening of mitral and/or tricuspid valves in $T g f b 3^{-/-}$fetuses. Notably, both outflow tract cushion and AV cushion defects are not present in all ${\mathrm{T} g f b 3^{-/}}^{-}$fetuses. The overall cardiovascular tissue expression of Tgfb3 is quite distinct but can slightly overlap to that of $T g f b 2$ during cardiovascular development [26,47]. It is possible that TGF $\beta 2$ could slightly compensate for the loss of TGF $\beta 3$ during development. These suggestions are consistent with the clinical findings indicating the presence of aortic and mitral valve diseases and aortic aneurysm in the LDS patients with genetic mutations in TGFB2 (LDS4) or TGFB3 (LDS5) $[9,38,48]$. Such a prediction is also supported by the observation that $T g f b 3$ deletion worsens embryonic developmental phenotypes of $T g f b 2$ knockout embryos [49]. Importantly, $T g f b 3$ expression increases in comparison to $T g f b 2$ during heart development [47]. This raises a possibility whether TGF $\beta 3$ could represent the predominant 
TGF $\beta$ isoform during later stages of cardiac remodeling, a suggestion consistent with the mutations in TGFB3 in adult cardiac disease patients [7,50].

TGFB3 mutations result in dysregulated collagen matrix reorganization and fibrotic lesions associated with the ventricular fibrosis and aortic or mitral valve disease [6]. Several studies have indicated that TGF $\beta$ signaling is required for collagen production, remodeling, and organization $[35,51,52]$. Collagen organization is critical for heart development, and structure and function in the adult myocardium and heart valves [28]. A direct role of TGF 33 on collagen reorganization has determined for the first time in this study. The data reveals that TGF $\beta 3$-deficient whole mouse fibroblasts are defective in their ability to reorganize the collagen matrix and that exogenous addition of higher doses of TGF $\beta 1$ can compensate for the loss of TGF $\beta 3$. This supports the hypothesis that loss of Tgfb3 results in a compensatory TGF $\beta$ ECM response. This failure of reorganization is indicative of altered contractile machinery and/or adhesion molecules [33]. TGFB3 mutations have also been reported in patients with mitral and aortic valve disease and that hyper-activated TGF $\beta$ signaling has been implicated in mammalian valve disease $[9,53]$. Thus, the results presented in this study, establishing a unique and important requirement of TGF $\beta 3$ in collagen fiber organization, are novel and represent a significant step which will increase our understanding of the role of TGF $\beta 3$ signaling in heart development and cardiac pathophysiology.

One of the observations and potential limitations of our study is the variable phenotypic penetrance of cardiovascular anomalies in $T g f b 3^{-/-}$mice, which hinders the morphometric comparison and the investigation of the underlying cellular, developmental, molecular and biochemical mechanisms. Given that pSMAD2/3 levels are not significantly increased in one third of cases of the mutant hearts, it is difficult to conclude from the results whether the increased pSMAD2/3 levels cause the cardiovascular malformations in the Tgfb3-/- fetuses. It is possible that increased TGF $\beta$ signaling instead represents a compensatory mechanism and that a failure to fully compensate for the loss of TGF $\beta 3$ signaling results in phenotypically variable cardiovascular anomalies in the $T g f b 3^{-/-}$fetuses. Such a prediction is consistent with more severe developmental phenotype and mid-gestational lethality reported in $T g f b 3$ and $T g f b 2$ double knockout embryos compared to the cardiovascular phenotypes reported in the Tgfb3 ${ }^{-/}$embryos in our study [49].

Another very significant finding in this study is that genetic disruption of $T g f b 3$ leads to impaired ventricular myocardium. Regulatory mutations in the TGFB3 associated with the increased TGF $\beta$ signaling have been identified in patients showing a typical ARVD1/C phenotype [7]. Notably, fibro-fatty replacement of the right ventricular myocardium in these ARVD1/C patients involves both fibrosis and myocardial apoptosis [6]. Our data suggest that TGF $\beta 3$-deficient hearts exhibit increased activation of SMAD-dependent (SMAD2/3 and SMAD1/5) and non-SMAD (p38 MAPK and ERK1/2 MAPK) pathways. TGF $\beta$ signaling via the SMAD2/3 pathways can induce the expression of extracellular matrix genes and the phenotypic transformation of fibroblasts into myofibroblasts, and stimulate pro-collagen and collagen synthesis [54]. Moreover, increased TGF $\beta$ signaling via the TRAF6-TAK1-p38 MAPK pathway can lead to apoptosis. In a remarkable study, Li et al. (2011) have shown that the loss of Jup1 (i.e., plakoglobin), which leads to impaired cell differentiation, increased myocardial apoptosis and fibrosis, and elevated TGF $\beta$ signaling causes ARVD1/C in mice [8]. Mutations in genes encoding desmosomal proteins including plakoglobin (JUP1) have also been reported in about half of the ARVC patients. Thus, it is possible that increased TGF $\beta$ signaling is a major and common underlying mechanism of ARVC pathogenesis. We provided histological and biochemical evidence showing that mild cardiovascular malformations (such as hypoplastic arterial walls, myocardial defects, OFT cushion defects) in $\mathrm{Tgfb}^{+/-}$embryos are also associated with hyper-activated canonical and noncanonical TGF $\beta$ signaling. This observation is quite similar to the increased SMAD2 activation seen in aortic tissue and fibroblasts of LDS5 and ARVD1/C patients harboring TGFB3 heterozygous mutations. Together, this suggests that increased TGF $\beta$ signaling may be a compensatory response to the loss of TGF $\beta 3$ and that the extent of TGF $\beta$ overactivation beyond a certain threshold (i.e., wildtype $<T g f b 3$ heterozygous $<T g f b 3$ homozygous) could result in range of cardiovascular pathomorphologies. Since this increased TGF $\beta$ signaling seems compatible with the survival of $T g f b 3^{+/-}$mice, it is possible that adult $T g f b 3^{+/-}$ 
mice will develop progressive cardiovascular disease such as aortic aneurysm, valvular heart disease, and cardiomyopathy. We are currently analyzing adult $T g \mathrm{fb}^{+/-}$mice at different ages in longitudinal studies to establish a correlation between TGF $\beta$ hyperactivation and development and progression of cardiovascular pathophysiology and disease (i.e., cardiac dysfunction, heart valve disease, aortic aneurysm via echocardiography).

In this study, we describe the abnormal vascular walls (aorta and pulmonary trunk) phenotype in both $T g f b 3$ heterozygous and $T g f b 3$ knockout fetuses, which nicely links this phenotype to LDS5 (human TGFB3 mutations). Our data also show the expression of Tgfb3 in the great vessels as well as in the condensed mesenchyme of the OFT septum, which is consistent with earlier findings [26]. That is a rare combination. Since, in the OFT (vascular and septation), the NCC interact with SHF [55-57], the total phenotypic outcomes in Tgfb3 mutants may be the effect of a lack of TGF $\beta 3$ on both cell types. Since adventitial fibroblasts receive arterial epicardial derived cells [58], it is possible that the epicardial cells in the abnormal vascular walls in $T g f_{b 3}-/-$ embryos could be defective. The myocardial defects described in this study may be based on a defective contribution of epicardium derived fibroblasts with a higher involvement (but not selective) of the RV. The atrioventricular valves, both mitral and tricuspid receive epicardial cells [58-60], and therefore TGF $\beta 3$ might play an important role in epicardial morphogenesis. $T g f b 3$ expression data support the idea that the role of epicardium is a crucial link to ventricular myocardial problems and the AV cushions [26,60]. Both ventricular myocardium and AV cushions receive epicardial cells that mainly differentiate into fibroblasts [58-60]. There is a difference in homing and timing of epicardium to RV and LV [61], which could explain why, in Tgfb3 $3^{-/-}$embryos, the RV is more involved, although surely the LV is also affected as well. There are several models in which epicardium is defective, either after mechanical removing the epicardium in the quail or in mouse mutant models (PDGFR $\alpha$, Podoplanin, RxR) [58,62]. All of these animal models present with very thin myocardium and a spongy ventricular septum with often muscular VSD. Recently, Tgfb3 conditional knockout mice have been generated [63] and will be useful in future investigation to determine the cell-specific role of TGF $\beta 3$ in cardiovascular development and adult cardiovascular disease. In conclusion, TGF $\beta 3$ is required for cardiovascular development in mice by maintaining a proper balance of downstream SMAD-dependent and MAPK-dependent TGF $\beta$ signaling mechanisms.

Supplementary Materials: The following are available online at http://www.mdpi.com/2308-3425/7/2/19/s1. Table S1. Cardiovascular defects in Tgfb3 knockout mice (Embryonic Day 13.5 to $18.5(\mathrm{n}=19)$. Figure S1. Systemic $T g f b 3$ deletion disrupts ventricular myocardial development and leads to muscular VSD. A-C, H\&E stained sections of wildtype and different $T g f b 3^{-/-}$fetuses (E15.5-16.5) showing abnormal size, shape, and myocardium of the right ventricle in $T g f b 3^{-/-}$(B,C, left arrow) and mitral valve thickening (B,C, arrowheads). The left ventricular myocardium in $\mathrm{Tgfb} 3^{-1-}$ fetuses (B,C, right arrow) was also not normal. D,E, Cardiac muscle actin (clone HHF35) immunohistochemistry of cross sections of E14.5-15.5 fetuses showing myocardium of both right and left ventricles was affected in some Tgfb3 $3^{-/-}$resulting in muscular VSD (E, arrow). F,G, H\&E stained sections of wildtype and $\mathrm{T}_{\mathrm{f}} \mathrm{b3^{+/- }}$ fetuses (E14.5-15.5) showing mild thinning of the right ventricular myocardium (G, left arrowhead) and moderately thickened left ventricular myocardium $\left(G\right.$, right arrowhead) in $T g f b 3^{+/-}$fetuses compared to wildtype heart (F). Scale bars: $200 \mu \mathrm{m}$ for A-G. Abbreviations: rv, right ventricle; lv, left ventricle; tv, tricuspid valve; mv, mitral valve. Figure S2. Tgfb3 deletion leads to pulmonary and aortic valve defects. A-D, Hematoxylin and eosin

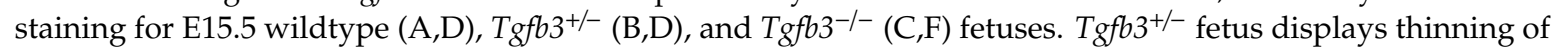
vascular walls of aorta and pulmonary trunk ( $B$, arrowheads), mild thickening of both pulmonary $(B$, arrow) and aortic (E, arrow) valves compared to wildtype fetus (A,B). Notably, Tgfb3 ${ }^{-/}$fetuses develop severe forms of these cardiovascular defects (C,F). Scale bars: $200 \mu \mathrm{m}$ for A-F. Figure S3. Abnormal ascending aortic walls in Tgfb3 knockout fetuses. A-D, Elastin autofluorescence $(C, D)$ of hematoxylin and eosin-stained $(A, B)$ sections. Compared to wildtype littermate (C), Tgfb3-/- fetus shows poorly formed elastic lamellae and disorganized vascular smooth muscle cells in the aortic wall (arrows, D). Fluorescence images (C,D) were taken from region of aorta indicated by boxes $(A, B)$. Arrows indicate elastic fibers $(C, D)$ and the white dotted lines demarcates the aortic wall from vaso vasorum (D). Scale bars $=100 \mu \mathrm{m}$ for A,B; $25 \mu \mathrm{m}$ for C,D. Figure S4. Measurement of aortic valve volume in Tgfb3 knockout fetuses. A-G, Morphometric comparison and volume measurements using AMIRA 3D segmentation of aortic valves from wildtype (A,C,E) and Tgfb3-/- (B,D,F) embryos (E15.5) showing non-coronary leaflets in red, left coronary leaflets in green, and the right coronary leaflets in yellow. The hyperplastic nature of the outflow tract cushions in $T g f b 3^{-l-}$ embryos compared to the wildtype littermate embryos (G). Student's $t$ test was used. 
$p$-Values are indicated in the histogram. Numerical data are presented as scatter dot-plots with boxes, with the box denoting the mean; error bars identify the S.E.M ( $n=3$ per genotype).

Author Contributions: Conceptualization, M.A. Methodology, M.C., N.A.-S., M.G.G., E.A.P., A.B., S.C., and J.J. Writing-Original draft preparation, M.A., M.C., and A.B. Writing-Review \& Editing, J.F.E., R.E.P., and A.C.G.-d.G. Supervision, M.A. Funding, M.A. All authors have read and agreed to the published version of the manuscript.

Funding: This work was supported by, in parts, funds from the University of South Carolina, the National Institutes of Health grants R01HL126705, R01HL145064, R01CA218578-1A1 and the American Heart Association grant 17GRNT33650018 (M.A), American Heart Association-Predoctoral Fellowship 18PRE34080051 (N.A.), and University of South Carolina-ASPIRE I Postdoctoral Award (M.C.).

Acknowledgments: We thank Lorain Junor, Shalom Hre, Qingbo Lou, Taylor Dunphy, Ipsita Pradhan, Kacey Booth, Zeeshan Ayub, Waqas Hussain, Pragya Jaiswal, and Kim McRae for their assistance in image processing and morphometric measurements, mouse genotyping, tissue processing and sectioning, and histology. We also thank the Instrumentation Resource Facility at the University of South Carolina School of Medicine and the Dorn VA Medical Center for the instrumentation support.

Conflicts of Interest: The authors declare no conflict of interest.

\section{References}

1. Proetzel, G.; Pawlowski, S.A.; Wiles, M.V.; Yin, M.; Boivin, G.P.; Howles, P.N.; Ding, J.; Ferguson, M.W.J.; Doetschman, T. Transforming growth factor-beta 3 is required for secondary palate fusion. Nat. Genet. 1995, 11, 409-414. [CrossRef]

2. Kaartinen, V.; Voncken, J.W.; Shuler, C.; Warburton, D.; Bu, D.; Heisterkamp, N.; Groffen, J. Abnormal lung development and cleft palate in mice lacking TGF- $\beta 3$ indicates defects of epithelial-mesenchymal interaction. Nat. Genet. 1995, 11, 415-421. [CrossRef]

3. Hu, L.; Liu, J.; Li, Z.; Ozturk, F.; Gurumurthy, C.; Romano, R.-A.; Sinha, S.; Nawshad, A. TGFß3 Regulates Periderm Removal Through $\triangle \mathrm{Np} 63$ in the Developing Palate. J. Cell. Physiol. 2015, 230, 1212-1225. [CrossRef]

4. Chopra, S.; Al-Sammarraie, N.; Lai, Y.; Azhar, M. Increased canonical WNT/ $\beta$-catenin signalling and myxomatous valve disease. Cardiovasc. Res. 2017, 113, 6-9. [CrossRef]

5. Azhar, M.; Ware, S.M. Genetic and Developmental Basis of Cardiovascular Malformations. Clin. Perinatol. 2016, 43, 39-53. [CrossRef]

6. Tamargo, J. TGF $\beta 3$ mutations cause arrhythmogenic right ventricular dysplasia type 1 and open the door to understanding the biological role of TGF 33 (where there's a will, there's a way). Cardiovasc. Res. 2012, 96, 188-190. [CrossRef]

7. Beffagna, G.; Occhi, G.; Nava, A.; Vitiello, L.; Ditadi, A.; Basso, C.; Bauce, B.; Carraro, G.; Thiene, G.; Towbin, J.A.; et al. Regulatory mutations in transforming growth factor-beta3 gene cause arrhythmogenic right ventricular cardiomyopathy type 1. Cardiovasc. Res. 2005, 65, 366-373. [CrossRef] [PubMed]

8. Li, D.; Liu, Y.; Maruyama, M.; Zhu, W.; Chen, H.; Zhang, W.; Reuter, S.; Lin, S.-F.; Haneline, L.S.; Field, L.J.; et al. Restrictive loss of plakoglobin in cardiomyocytes leads to arrhythmogenic cardiomyopathy. Hum. Mol. Genet. 2011, 20, 4582-4596. [CrossRef] [PubMed]

9. Bertoli-Avella, A.M.; Gillis, E.; Morisaki, H.; Verhagen, J.M.; De Graaf, B.M.; Van De Beek, G.; Gallo, E.; Kruithof, B.P.; Venselaar, H.; Myers, L.A.; et al. Mutations in a TGF- $\beta$ ligand, TGFB3, cause syndromic aortic aneurysms and dissections. J. Am. Coll. Cardiol. 2015, 65, 1324-1336. [CrossRef] [PubMed]

10. Schepers, D.; Tortora, G.; Morisaki, H.; MacCarrick, G.; Lindsay, M.; Liang, D.; Mehta, S.G.; Hague, J.; Verhagen, J.M.; Van De Laar, I.M.; et al. A mutation update on the LDS-associated genes TGFB2/3 and SMAD2/3. Hum. Mutat. 2018, 39, 621-634. [CrossRef]

11. Mégarbané, A.; Deepthi, A.; Obeid, M.; Al-Ali, M.T.; Gambarini, A.; El-Hayek, S. Homozygous deletion of exons 2-7 within TGFB3 gene in a child with severe Loeys-Dietz syndrome and Marfan-like features. Am. J. Med. Genet. Part A 2020, 182, 1230-1235. [CrossRef]

12. Matyas, G.; Naef, P.; Tollens, M.; Oexle, K. De novo mutation of the latency-associated peptide domain of TGFB3 in a patient with overgrowth and Loeys-Dietz syndrome features. Am. J. Med. Genet. Part A 2014, 164, 2141-2143. [CrossRef] [PubMed] 
13. Rienhoff, H.Y.; Yeo, C.-Y.; Morissette, R.; Khrebtukova, I.; Melnick, J.; Luo, S.; Leng, N.; Kim, Y.-J.; Schroth, G.; Westwick, J.; et al. A mutation in TGFB3 associated with a syndrome of low muscle mass, growth retardation, distal arthrogryposis and clinical features overlapping with marfan and loeys-dietz syndrome. Am. J. Med. Genet. Part A 2013, 161, 2040-2046. [CrossRef] [PubMed]

14. Rienhoff, H.Y. Response to "De novo mutation of the TGFB3 latency-associated peptide domain in a patient with overgrowth and Loeys-Dietz syndrome features". Am. J. Med. Genet. Part A 2014, 164, $2144-2145$. [CrossRef]

15. Akhurst, R.J. The paradoxical TGF-beta vasculopathies. Nat. Genet. 2012, 44, 838-839. [CrossRef] [PubMed]

16. Doetschman, T.; Barnett, J.V.; Runyan, R.; Camenisch, T.D.; Heimark, R.L.; Granzier, H.L.; Conway, S.J.; Azhar, M. Transforming growth factor beta signaling in adult cardiovascular diseases and repair. Cell Tissue Res. 2011, 347, 203-223. [CrossRef] [PubMed]

17. Dobaczewski, M.; Chen, W.; Frangogiannis, N.G. Transforming growth factor (TGF)-beta signaling in cardiac remodeling. J. Mol. Cell Cardiol. 2011, 51, 600-606. [CrossRef]

18. Morikawa, M.; Derynck, R.; Miyazono, K. TGF- $\beta$ and the TGF- $\beta$ Family: Context-Dependent Roles in Cell and Tissue Physiology. Cold Spring Harb. Perspect. Boil. 2016, 8, a021873. [CrossRef]

19. Markwald, R.R.; Norris, R.A.; Moreno-Rodriguez, R.; Levine, R.A. Developmental basis of adult cardiovascular diseases: Valvular heart diseases. Ann. N. Y. Acad. Sci. 2010, 1188, 177-183. [CrossRef]

20. Goumans, M.J.; Dijke, P.T. TGF- $\beta$ Signaling in Control of Cardiovascular Function. Cold Spring Harb. Perspect. Boil. 2018, 10, a022210. [CrossRef]

21. Hill, C.S. Transcriptional Control by the SMADs. Cold Spring Harb. Perspect. Boil. 2016. [CrossRef]

22. Ramachandran, A.; Vizan, P.; Das, D.; Chakravarty, P.; Vogt, J.; Rogers, K.; Müller, P.; Hinck, A.P.; Sapkota, G.P.; Hill, C.S. TGF- $\beta$ uses a novel mode of receptor activation to phosphorylate SMAD1/5 and induce epithelial-to-mesenchymal transition. eLife 2018, 7. [CrossRef] [PubMed]

23. Mu, Y.; Gudey, S.; Landström, M. Non-Smad signaling pathways. Cell Tissue Res. 2011, 347, 11-20. [CrossRef]

24. Doetschman, T. Interpretation of phenotype in genetically engineered mice. Lab. Anim. Sci. 1999, 49, 137-143. [PubMed]

25. Heldin, C.-H.; Moustakas, A. Signaling Receptors for TGF- $\beta$ Family Members. Cold Spring Harb. Perspect. Boil. 2016, 8. [CrossRef]

26. Molin, D.G.; Bartram, U.; Van der Heiden, K.; Van Iperen, L.; Speer, C.P.; Hierck, B.P.; Poelmann, R.E.; Gittenberger-de-Groot, A.C. Expression patterns of Tgfbeta1-3 associate with myocardialisation of the outflow tract and the development of the epicardium and the fibrous heart skeleton. Dev. Dyn. 2003, 227, 431-444. [CrossRef]

27. Rampazzo, A.; Beffagna, G.; Nava, A.; Occhi, G.; Bauce, B.; Noiato, M.; Basso, C.; Frigo, G.; Thiene, G.; Towbin, J.; et al. Arrhythmogenic right ventricular cardiomyopathy type 1 (ARVD1): Confirmation of locus assignment and mutation screening of four candidate genes. Eur. J. Hum. Genet. 2003, 11, 69-76. [CrossRef] [PubMed]

28. Frangogiannis, N.G. Fibroblasts and the extracellular matrix in right ventricular disease. Cardiovasc. Res. 2017, 113, 1453-1464. [CrossRef]

29. Azhar, M.; Brown, K.; Gard, C.; Chen, H.; Rajan, S.; Elliott, D.A.; Stevens, M.V.; Camenisch, T.D.; Conway, S.J.; Doetschman, T. Transforming growth factor Beta 2 is required for valve remodeling during heart development. Dev. Dyn. 2011, 240, 2127-2141. [CrossRef]

30. Menon, V.; Eberth, J.F.; Goodwin, R.L.; Potts, J.D. Altered Hemodynamics in the Embryonic Heart Affects Outflow Valve Development. J. Cardiovasc. Dev. Dis. 2015, 2, 108-124. [CrossRef]

31. Wang, F.; Flanagan, J.; Su, N.; Wang, L.-C.; Bui, S.; Nielson, A.; Wu, X.; Vo, H.-T.; Ma, X.-J.; Luo, Y. RNAscope: A novel in situ RNA analysis platform for formalin-fixed, paraffin-embedded tissues. J. Mol. Diagn. 2012, 14, 22-29. [CrossRef] [PubMed]

32. Todaro, G.J.; Green, H. Quantitative studies of the growth of mouse embryo cells in culture and their development into established lines. J. Cell Boil. 1963, 17, 299-313. [CrossRef] [PubMed]

33. Lane, B.A.; Harmon, K.A.; Goodwin, R.L.; Yost, M.J.; Shazly, T.; Eberth, J.F. Constitutive modeling of compressible type-I collagen hydrogels. Med. Eng. Phys. 2018, 53, 39-48. [CrossRef] [PubMed]

34. Haskett, D.; Doyle, J.J.; Gard, C.; Chen, H.; Ball, C.; Estabrook, M.A.; Encinas, A.C.; Dietz, H.C.; Utzinger, U.; Geest, J.P.V.; et al. Altered tissue behavior of a non-aneurysmal descending thoracic aorta in the mouse model of Marfan syndrome. Cell Tissue Res. 2011, 347, 267-277. [CrossRef] [PubMed] 
35. Snider, P.; Hinton, R.B.; Moreno-Rodriguez, R.A.; Wang, J.; Rogers, R.; Lindsley, A.; Li, F.; Ingram, D.A.; Menick, D.; Field, L.; et al. Periostin is required for maturation and extracellular matrix stabilization of noncardiomyocyte lineages of the heart. Circ. Res. 2008, 102, 752-760. [CrossRef]

36. Poelmann, R.E.; Groot, A.C.G.-D. Apoptosis as an instrument in cardiovascular development. Birth Defects Res. C 2005, 75, 305-313. [CrossRef]

37. Ferguson, M.W.J. Craniofacial malformations: Towards a molecular understanding. Nat. Genet. 1994, 6, 329-330. [CrossRef]

38. Loeys, B.L.; Dietz, H.C. Loeys-Dietz Syndrome. In Gene Reviews [Internet]; Adam, M.P., Ardinger, H.H., et al., Eds.; University of Washington: Seattle, WA, USA, 2018; pp. 1993-2020. Available online: https: //www.ncbi.nlm.nih.gov/books/NBK1133/ (accessed on 23 April 2020).

39. Bartram, U.; Molin, D.G.; Wisse, L.J.; Mohamad, A.; Sanford, L.P.; Doetschman, T.; Speer, C.P.; Poelmann, R.E.; Gittenberger-de Groot, A.C. Double-outlet right ventricle and overriding tricuspid valve reflect disturbances of looping, myocardialization, endocardial cushion differentiation, and apoptosis in Tgfb2 knockout mice. Circulation 2001, 103, 2745-2752. [CrossRef]

40. Mercado-Pimentel, M.E.; Runyan, R. Multiple Transforming Growth Factor- $\beta$ Isoforms and Receptors Function during Epithelial-Mesenchymal Cell Transformation in the Embryonic Heart. Cells Tissues Organs 2007, 185, 146-156. [CrossRef]

41. Azhar, M.; Runyan, R.; Gard, C.; Sanford, L.P.; Miller, M.L.; Andringa, A.; Pawlowski, S.; Rajan, S.; Doetschman, T.; Doetschman, T. Ligand-specific function of transforming growth factor beta in epithelial-mesenchymal transition in heart development. Dev. Dyn. 2009, 238, 431-442. [CrossRef]

42. Hoover, L.L.; Burton, E.G.; O’Neill, M.L.; Brooks, B.A.; Sreedharan, S.; Dawson, N.A.; Kubalak, S.W. Retinoids regulate TGF $\beta$ signaling at the level of Smad2 phosphorylation and nuclear accumulation. Biochim. et Biophys. Acta (BBA)-Bioenerg. 2008, 1783, 2279-2286. [CrossRef] [PubMed]

43. Kubalak, S.W.; Hutson, D.R.; Scott, K.K.; Shannon, R.A. Elevated transforming growth factor beta2 enhances apoptosis and contributes to abnormal outflow tract and aortic sac development in retinoic $\mathrm{X}$ receptor alpha knockout embryos. Development 2002, 129, 733-746. [PubMed]

44. Walker, D.L.; Vacha, S.J.; Kirby, M.L.; Lo, C. Connexin43 deficiency causes dysregulation of coronary vasculogenesis. Dev. Boil. 2005, 284, 479-498. [CrossRef] [PubMed]

45. Guner-Ataman, B.; Paffett-Lugassy, N.; Adams, M.S.; Nevis, K.R.; Jahangiri, L.; Obregon, P.; Kikuchi, K.; Poss, K.D.; Burns, C.E.; Burns, C.G. Zebrafish second heart field development relies on progenitor specification in anterior lateral plate mesoderm and nkx2.5 function. Development 2013, 140, 1353-1363. [CrossRef]

46. Watanabe, M.; Jafri, A.; Fisher, S.A. Apoptosis Is Required for the Proper Formation of the Ventriculo-Arterial Connections. Dev. Boil. 2001, 240, 274-288. [CrossRef]

47. Vrljicak, P.; Chang, A.C.Y.; Morozova, O.; Wederell, E.D.; Niessen, K.; Marra, M.A.; Karsan, A.; Hoodless, P. Genomic analysis distinguishes phases of early development of the mouse atrio-ventricular canal. Physiol. Genom. 2009, 40, 150-157. [CrossRef]

48. Lindsay, M.E.; Schepers, D.; Bolar, N.A.; Doyle, J.J.; Gallo, E.; Fert-Bober, J.; Kempers, M.J.; Fishman, E.K.; Chen, Y.; Myers, L.; et al. Loss-of-function mutations in TGFB2 cause a syndromic presentation of thoracic aortic aneurysm. Nat. Genet. 2012, 44, 922-927. [CrossRef]

49. Dunker, N.; Krieglstein, K. Tgfbeta2 ${ }^{-/-}$Tgfbeta $^{-/-}$double knockout mice display severe midline fusion defects and early embryonic lethality. Anat. Embryol. 2002, 206, 73-83.

50. Hu, B.C.; Li, L.; Sun, R.; Gao, P.; Zhu, D.; Wang, J.-G.; Chu, S.-L. The association between transforming growth factor $\beta 3$ polymorphisms and left ventricular structure in hypertensive subjects. Clin. Chim. Acta 2010, 411, 558-562. [CrossRef]

51. Khalil, H.; Kanisicak, O.; Prasad, V.; Correll, R.N.; Fu, X.; Schips, T.G.; Vagnozzi, R.J.; Liu, R.; Huynh, T.; Lee, S.-J.; et al. Fibroblast-specific TGF- $\beta$-Smad2/3 signaling underlies cardiac fibrosis. J. Clin. Investig. 2017, 127, 3770-3783. [CrossRef]

52. Fix, C.; Carver-Molina, A.; Chakrabarti, M.; Azhar, M.; Carver, W. Effects of the isothiocyanate sulforaphane on TGF- $\beta 1$-induced rat cardiac fibroblast activation and extracellular matrix interactions. J. Cell. Physiol. 2019, 234, 13931-13941. [CrossRef]

53. Ng, C.M.; Cheng, A.; Myers, L.A.; Martínez-Murillo, F.; Jie, C.; Bedja, D.; Gabrielson, K.L.; Hausladen, J.M.; Mecham, R.P.; Judge, D.P.; et al. TGF- $\beta$-dependent pathogenesis of mitral valve prolapse in a mouse model of Marfan syndrome. J. Clin. Investig. 2004, 114, 1586-1592. [CrossRef] 
54. Murata, H.; Zhou, L.; Ochoa, S.; Hasan, A.; Badiavas, E.; Falanga, V. TGF- $\beta 3$ Stimulates and Regulates Collagen Synthesis Through TGF- $\beta 1-D e p e n d e n t$ and Independent Mechanisms. J. Investig. Dermatol. 1997, 108, 258-262. [CrossRef]

55. Groot, A.C.G.-D.; Calkoen, E.E.; Poelmann, R.E.; Bartelings, M.M.; Jongbloed, M.R.M. Morphogenesis and molecular considerations on congenital cardiac septal defects. Ann. Med. 2014, 46, 640-652. [CrossRef]

56. Conway, S.J.; Kaartinen, V. TGFbeta superfamily signaling in the neural crest lineage. Cell Adh. Migr. 2011, 5, 232-236. [CrossRef]

57. Neeb, Z.; Lajiness, J.D.; Bolanis, E.; Conway, S.J. Cardiac outflow tract anomalies. Wiley Interdiscip. Rev. Dev. Boil. 2013, 2, 499-530. [CrossRef]

58. Groot, A.C.G.-D.; Winter, E.M.; Bartelings, M.M.; Goumans, M.J.; DeRuiter, M.C.; Poelmann, R.E. The arterial and cardiac epicardium in development, disease and repair. Differentiation 2012, 84, 41-53. [CrossRef]

59. Lockhart, M.M.; Hoff, M.V.D.; Wessels, A. The Role of the Epicardium in the Formation of the Cardiac Valves in the Mouse. In Etiology and Morphogenesis of Congenital Heart Disease; Springer Science and Business Media LLC: Berlin, Germany, 2016; pp. 161-167.

60. Wessels, A.; Pérez-Pomares, J.M. The epicardium and epicardially derived cells (EPDCs) as cardiac stem cells. Anat. Rec. Part A Discov. Mol. Cell. Evol. Boil. 2003, 276, 43-57. [CrossRef]

61. Vicente-Steijn, R.; Scherptong, R.W.C.; Kruithof, B.P.T.; Duim, S.N.; Goumans, M.J.T.H.; Wisse, L.J.; Zhou, B.; $\mathrm{Pu}$, W.T.; Poelmann, R.E.; Schalij, M.J.; et al. Regional differences in WT-1 and Tcf21 expression during ventricular development: Implications for myocardial compaction. PLoS ONE 2015, 10. [CrossRef]

62. Poelmann, R.E.; Groot, A.C.G.-D.; Vicente-Steijn, R.; Wisse, L.J.; Bartelings, M.M.; Everts, S.; Hoppenbrouwers, T.; Kruithof, B.P.T.; Jensen, B.; De Bruin, P.W.; et al. Evolution and Development of Ventricular Septation in the Amniote Heart. PLoS ONE 2014, 9. [CrossRef]

63. Doetschman, T.; Georgieva, T.; Li, H.; Reed, T.D.; Grisham, C.; Friel, J.; Estabrook, M.A.; Gard, C.; Sanford, L.; Azhar, M. Generation of mice with a conditional allele for the transforming growth factor beta3 gene. Genes 2012, 50, 59-66. [CrossRef] [PubMed]

Sample availability: not available.

(C) 2020 by the authors. Licensee MDPI, Basel, Switzerland. This article is an open access article distributed under the terms and conditions of the Creative Commons Attribution (CC BY) license (http://creativecommons.org/licenses/by/4.0/). 